Composite Nanofibers as Advanced Materials for Li-ion, Li-O $\mathrm{O}_{2}$ and Li-S Batteries Victor A, Agubra, Luis Zuniga, David Flores, Jahaziel Villareal, Mataz Alcoutlabi* Mechanical Engineering Department, University of Texas, Rio Grande Valley, Edinburg, TX 78539

*Corresponding Author. Tel: 956-665-8945. Email: Mataz.alcoutlabi@utrgv.edu 
Keywords: Lithium ion batteries, Nanofibers, Electrode, Separator, Li Sulfur batteries, Li air batteries

\section{Contents}

1. Introduction 3

2. Nanofibers (NFs) Production Techniques 5

3. Carbon Nanofiber (CNFs) anodes $\quad 7$

$\begin{array}{lr}\text { 4.0. Lithium alloy-CNFs anode materials } & 10\end{array}$

4.1 Tin Carbon nanofibers composites 11

4.1.1 Sn/C composite nanofibers 11

4.2. Si/Carbon composite nanofibers $\quad 12$

4.2.1 Si/C composite nanofiber anode 13

4.3 Ferriferous oxide /Carbon nanofibers anode 14

5. Lithium metal oxide-CNFs cathode materials 15

5.1. Composite nanofibers for Li/S battery cathode 16

5.2. Composite nanofibers for Li-air battery cathodes 18

6. Polymeric Nanofiber Separators 19

$\begin{array}{ll}6.1 \text { Nonwoven fibrous polymer membrane separators } & 20\end{array}$

6.2. Improvement Trends 22

6.2.1 Coating separators with ceramic particles 22

6.2.2 Coating separators with polymer nanofiber (NFs) 22

$\begin{array}{ll}\text { 7. Conclusions } & 24\end{array}$ 
References

\section{Introduction}

The use of nanostructured materials for energy storage devices has been the trend in recent years. Nanostructured fibers made from metals, metal oxides, polymers, ceramics, and composites have been developed for use in various energy storage devices such as high-performance rechargeable lithium (Li) batteries (e.g. Li-ion, Li-sulfur, and Li-air batteries), sodium (Na), magnesium $(\mathrm{Mg})$, aluminum (Al) and zinc $(\mathrm{Zn})$ batteries and supercapacitors[1-18]. The popularity of these nanofibers stem from the many attributes such as; controllable fiber diameter, high surface areato-volume ratio, low density, and high pore volume $[6,19-21]$. These properties make the nanofiber structure more advantageous when used in LIBs as they deliver a superior electrochemical properties; stable cycle performance, enhanced capacity, superior low temperature performance [21-24], compared to their powder, crystal, nanowire, thin film, etc. counterparts[25-29]. The sterling properties/performance of nanofibers have seen their wide applications in lithium ion batteries (as electrode and separators materials), supercapacitors, and chemical sensors [30-33]. There are several methods employed to produce these nanofibers, with the most common include; electrostatic charge (electrospinning), external heated air jets (meltblowing), bicomponent fiber spinning, phase separation, template synthesis, self-assembly, chemical vapor deposition, wet chemical synthesis, Nozzle-Free centrifugal or rotary jetspinning, and the emerging Forcespinning method [34-43].

Non-woven fibrous mats that have high surface area are typically in the range of a few micron to about $200 \mathrm{~nm}$ in diameter. Many efforts have been made to further reduce the fiber diameter into 
the nano scale [44]. This has been demonstrated through methods such as electrospinning, centrifugal spinning, and Forcespinning® (Fig.1a) that can produce fibrous mats of thickness of $10-20 \mu \mathrm{m}$ with fiber diameters that are typically less than $5 \mu \mathrm{m}[36,38,45-48]$. These fiber processing methods have been successful in giving the nanofibers their high labyrinth-like pores structure. The simplicity, high efficiency, low cost, high reproducibility, comparatively environmentally benign, and the ability to scale up for mass production of these methods have significantly increased their applicability [35, 46, 49]. There is considerable work on the use of structured composite nanofibers with high surface and interfacial areas to improve the performance of electrodes and separators in lithium ion batteries $[1,2,4,6,10,25,50-53]$. While there are several topics discussed in this article on the application of structured nanofibers, the main thrust of this review is to discuss the use of nanofibrous structure materials as electrodes and separators and their electrochemical performance in the lithium ion batteries.

\section{Nanofibers (NFs) Production Techniques}

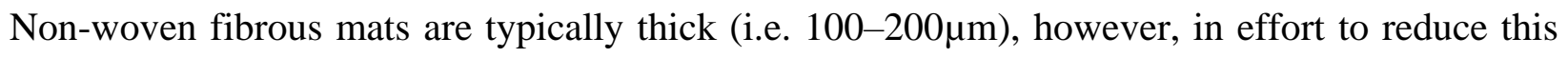
thickness, recent fiber manufacturing technology such as electrospinning(Fig.1b), centrifugal jet spinning, and Forcespinning ${ }^{\circledR}$ have emerged as promising methods to produce fibers with thickness of $10-20 \mu \mathrm{m}$ and diameters that are typically less than $5 \mu \mathrm{m}$ [54-60]. These fiber processing methods have been successful in giving the non-woven nanofiber mat their high labyrinth-like pores structure [57]. Presently the most commonly used methods for making these nanofibers employ either an electrostatic charge (electrospinning) [57, 61-63] or external heated air jets (melt-blowing) bicomponent fiber spinning, phase separation, template synthesis, and 
self-assembly [64-69]. These methods are often complex and for the past decade they has been used only to make nanofibers from limited types of polymers, often lab-scale in nature.

Electrospinning is also by far the method of choice for producing nanofibers (NFs), however it faces several drawbacks such as high electric fields requirement, solutions with better dielectric properties, and many other safety related issues. Many polymeric materials can be electrospun into fibers; however, electrospinning may not be suitable for mass production of certain materials and faces several restrictions regarding safety, especially for melt electrospinning where a high current is applied to the melt to form the fibers followed by stretching, structuring and cooling $[48,70-76]$. However, the large scale production challenge of electrospinning is set to see an end in sight, with Jiangxi Advanced Nanofiber Technology Co., Ltd mass producing polyimide nanofiber separators for advanced lithium-ion in a scale of $3000 \mathrm{~m}^{2} / \mathrm{day}$ [patent is available at: http://www.faqs.org/patents/app/20130164629]. Forcespinning (FS) has been used to prepare fibers from a wide range of materials due to the fact that FS can produce fibers from melt and solutions without the need of applying an electric field during processing. Furthermore, the FS method has proven to be suitable for mass production of nanofibers for biomedical, energy storage, defense and aerospace-related-applications [39, 55, 77-80]. In the FS method (Fig.1a), the electric field used in the electrospinning process is replaced by centrifugal forces to overcome the polymer/material surface tension and therefore stretching the fibers $[38,39,77,81$ 84].

The production of NFs by a FS lab scale system is higher than 60 grams/hr which is much higher than the yield obtained by electrospinning (approximately i.e. 0.1 grams/hour) [46, 85]. Several NFs systems and polymer composites have been recently produced by the FS system [38, 77, 82 84, 86]. In these NFs systems, the fibers were produced with average fiber diameters in the nano 


\section{Carbon Nanofiber (CNFs) anodes}


Recently, there has been an extensive research activities focusing on the development of nanostructured anode materials in the view of enhancing the capacity, energy density and specific power of rechargeable lithium-ion batteries [92-97]. In nanofiber processing such as electrospinning and Forcespinning, a polymer precursor is usually used to produce nanofibers that will be transformed into carbon nanofibers after different thermal treatments (carbonization). The produced carbon nanofiber mats can be very often brittle. This can be avoided by carrying out a stabilization process in air (i.e. oxidative stabilization) on the polymer nanofiber precursor prior to carbonization. The yield of carbon nanofibers depends on several factors including the polymer-type used during nanofiber spinning. In general, the behavior of polymeric materials is time, temperature and pressure dependent [98-100], therefore, the nanofiber morphology and structure are significantly dependent on the polymer concentration and the chemical structure of the polymer used to prepare the nanofiber precursor.

Carbon nano fibers (CNFs) have been widely used as anode material to replace commercial graphite particles for LIBs [23, 101-104]. Graphitized stacked-cup carbon nanofiber, highly porous CNFs, and ultra-long thin align carbon fibers have been produced by electrospinning as alternate anode materials [25, 28, 105-108]. Carbon nanofibers can be prepared by carbonization of different types of precursor polymer nanofibers, such as polyacrylonitrile (PAN), polyimide (PI), and pitch $[52,77,109]$. The carbonization temperature can be adjusted to control the carbon crystalline structure and, hence, the electrochemical properties of carbon nanofibers.

The CNFs produced from these precursors have smaller diameters and larger surface area to volume ratio $[23,101,103]$. A typical morphology and structure of the CNFs produced though the Forcespinning technique is shown in Figure 3. A large amount of defects in CNFs such as lattice and surface defects along the fiber length are expected to promote fast $\mathrm{Li}$ intercalation/de- 
intercalation. These physical properties of the CNFs promote fast ion transport, high accessibility of electrolyte, and shortens the $\mathrm{Li}^{+} /$electron diffusion path that is often attributed to the large surface area of nanofibers and their large pore volume [23, 102]. There is often a correlation between these physical properties of CNFs with the electrochemical performance of CNFs-based electrode in lithium ion batteries.

Several studies report a specific reversible capacity between $400-600 \mathrm{mAhg}^{-1}$ and excellent cycling performance after 50 cycles for CNFs anodes [31, 101-103]. Comparatively, the electrochemical performance of CNFs anodes is much better than that for commercial graphite anode with a theoretical capacity of $372 \mathrm{mAhg}^{-1}$. However, the loose structure of these nanofibers result in a low tap density, thus most of CNFs materials do not show much advantage compared to graphite anode ( $\sim 10$ micron in particle size) when based on the volumetric energy density of the electrode. In fact, the graphite is so far the best anode material to use in commercial LIBs due to its long cycle life, low cost and good capacity retention, even after hundreds of charge/discharge cycles, though its charge/discharge capacity is lower than ceramic composite nanofibers. There is no other anode materials that can compete with graphite at this time, although extensive research has been carried out to improve the performance and cycle stability of $\mathrm{Si} / \mathrm{C}$ or $\mathrm{Sn} / \mathrm{C}$ composite anodes. Theoretically, $\mathrm{Si}$ or $\mathrm{Sn}$ based anodes give a high capacity and might replace graphite anode in commercial LIBs in 50 years or so. This needs more work and effort to be done to improve the cycle stability and capacity retention of $\mathrm{Si} / \mathrm{C}$ composite NF anodes. The apparent good electrochemical performance of CNFs anode has often been the driving force for the huge interest among researchers. However, often the carbon nanofiber mats produced using some of these common techniques are not flexible after the carbonization process. It is therefore a common practice to grind the brittle CNFs with conductive carbon black 
to increase conductivity and adding binding agents to produce a slurry for the electrode making process $[5,71,110-112]$. The grinding of the rather uniform nanofiber compromises the fibrous nature of the nanofiber and its intended purpose. Another challenge of CNFs is the low fiber yield (i.e. 0.1 grams/hr for electrospinning) produced by most of the techniques, thus limiting the scaling up production of these CNFs [71, 112-119]. There is however an end in sight for the low fiber yield challenge with the recent introduction of Forcespinning into the nanofiber production techniques mix. The Forcespinning has the capability of producing fiber yield greater than 60 grams/hr, less expensive process, and environmentally safer [38, 46, 77] compared to electrospinning.

The successes of CNFs and their associated electrochemical performance have boosted the research in the area of lithium alloys-based electrodes for lithium ion batteries. Several research activities have been reported on composite electrodes comprising various metals and metal oxides and CNFs as electrode and separators for LIBs [107, 109, 120-126]. It is still early for these composite nanofibers to be used as electrodes in commercial lithium ion batteries. The loose structure of composite nanofibers itself, is an undesired property for lithium ion batteries due the low tap density. The ensuing discussion will focus on the use of CNFs as separators and electrodes for lithium ion batteries. Generally, the capacity and energy density of lithium ion batteries depend largely on the cathode material capacity. However, noticeable improvement of the overall capacity and energy density of the cell is often observed when using an alternate anode material having a capacity of the order of $1000 \mathrm{mAg}^{-1}$ which is much higher than that of carbonaceous electrode $\left(372 \mathrm{mAhg}^{-1}\right)$ material.

The driving force for such a replacement of a carbonaceous material lie in the fact that the potential of the anode vs $\mathrm{Li} / \mathrm{Li}^{+}$should be close to $0 \mathrm{~V}$ and not necessarily an intercalation type of 
electrochemical reaction as pertaining in the graphite anode. Alloying $\mathrm{Li}^{+}$with several viable metals and metal oxides such as $\mathrm{Si}, \mathrm{SiO}_{2}, \mathrm{Ge}, \mathrm{Fe}, \mathrm{Fe}_{2} \mathrm{O}_{3}, \mathrm{Ag}, \mathrm{Pb}, \mathrm{Sn}, \mathrm{SnO}_{2}$ etc. are potential candidates for use as anodes in LIBs $[96,113,127,128]$. The $\mathrm{Lix} \mathrm{M}$ (where $\mathrm{M}=\mathrm{Sn}, \mathrm{Si}, \mathrm{FeO}_{2} \mathrm{O}_{3}$, etc.) alloys show a much higher Li:M ratio at the end of the charge cycle therefore allowing a greater $\mathrm{Li}^{+}$accommodation. Therefore these lithium alloys have higher capacity and energy density than commercial graphite anode. However, the major challenge for these Li:M alloys is that they are known to degrade rapidly from their high theoretical specific capacity of 998-3600 $\mathrm{mAhg}^{-1}$ due to several factors including high volume change during the alloying/de-alloying process which can lead to pulverization and poor cyclability [129-131]. Nanofiber metal/metal oxides composite anodes have been an emerging trend where several research have employed metal/carbon composite nanofibers in a bid to either curb or minimize the high volumetric change of these Li: M alloys [5, 132, 133]. The fibrous structure of the nanofiber electrode provides ample room to accommodate the volume changes during the alloying/de-alloying process. We discuss below recent progress and development reported on the use of metal/CNFs as anodes for LIBs.

\section{Lithium alloy-CNFs anode materials}

Lithium alloys and carbonaceous materials are two classes of anode materials for lithium-ion batteries. Both materials have shortcomings (e.g., low charge capacity for carbon and low cycle life for lithium alloy) that limit the performance of lithium-ion batteries. Metal and metal oxide/carbon nanostructured composite such as $\mathrm{Sn} / \mathrm{CNFs}, \mathrm{Si} / \mathrm{CNFs}, \mathrm{SiO}_{2} / \mathrm{CNFs}, \mathrm{SnO}_{2} / \mathrm{CNFs}$, $\mathrm{TiO}_{2} / \mathrm{CNFs}$ and Ferriferous oxide/CNFs have been widely used as anodes for LIBs $[1,25,134-$ 137]. Some of these anodes are discussed in the following section. 


\subsection{Tin/Carbon composite nanofibers}

Tin (Sn)-based derivatives such as tin oxides, tin sulfides, and stannates have become attractive anode materials for LIBs [5, 138-140]. The popularity of these Sn-based lithium alloys stem from their properties such as; the inhibition of solvent co-intercalation and significant improvement in performance over the commercial graphite anode in LIBs [112, 115, 141-143]. In addition, $\mathrm{Sn} /$ carbon composite nanofibers have been studied for use as anodes in LIBs because they are easy to process and they exhibit lower potential hysteresis compared to other transition metal oxides [144]. Sn/CNFs composite are capable of hosting a higher amount of lithium ions in tin crystal structure, i.e. about four (4) atoms (i.e. $\mathrm{Li}_{x} \mathrm{Sn}, 0<\mathrm{X} \leq 4.4$ ) compared to carbonaceous anode (i.e. $\mathrm{LixC}_{6}, 0<\mathrm{X} \leq 1$ ) thereby giving $\mathrm{Sn} / \mathrm{C}$ composite a higher lithium storage capacity.

$\mathrm{Sn} /$ carbon composite nanofibers show excellent reversible capacity and cyclic performance, even at a higher current rate of $200 \mathrm{mAg}^{-1}$ to $1 \mathrm{Ag}^{-1}[5,138,139]$. This performance has been found to depend largely on the carbonization temperature which tend to have a direct impact on the fiber morphology, structure and the pore distribution [5, 139], as shown in Figure 3. There are varying reports on the influence of Sn particles size on the overall composite Sn/CNFs electrode performance. While some of these anodes show a higher reversible capacity with a Sn particle size in the nano range $(>5 \mathrm{~nm})[102,137]$, other studies reported no significant difference in the particle size influence on electrochemical performance [145-147]. A smaller particle size largely will generally offer a higher surface area and aspect ratio, which offer the electrode more reactive sites for electrochemical reaction, however nano-size particles are equally prone to agglomeration which could affect their uniform dispersion in the polymer matrix. 


\subsection{1 $\mathrm{Sn} / \mathrm{C}$ composite nanofibers}

Ternary composites of Sn/CNFs incorporating or containing other metals and their oxides have been designed to further improve the conductivity, the cyclic and rate performance of LIBs. $\mathrm{SnO}_{2} / \mathrm{ZnO}$ heterogeneous nanofiber [104, 148], Nitrogen doped CNFs with quantum dots Sn [123], Co-Sn alloy carbon nanofibers[149], and $\mathrm{Fe}_{3} \mathrm{O}_{4} / \mathrm{SnO}_{2}$ coaxial nanofibers [150] have been investigated. The $\mathrm{N}$-doped $\mathrm{Sn} / \mathrm{CNF}$ 's for instance, provides fast and versatile electrolyte transport and acts as efficient electron transport pathways and stable mechanical support for keeping the structural integrity of the electrodes during cycling and preventing pulverization of the composite electrode [123], while the Cobalt in the Sn/CNFs minimizes the volume expansion and enhances the electrical conductivity of the electrode $[149,151]$. The electrochemical performance of Sn and its composite derivatives (Figure 4) shows a very remarkable cyclic performance when they are used as $\mathrm{Sn} / \mathrm{CNF}$ composite electrode. These composites still show a remarkable capacity retention at high current densities (Fig. 5). The CNFs/ Sn based composite electrode can inevitably reduce the volume change (i.e. > 260\%) that result from alloying/de-alloying processes that sometimes lead to particle isolation and disconnectivity between the electrical conductive particles during cycling (i.e. charge/discharge process). Although Sn/CNFs-based composites are considered good alternative anodes for LIBs, their inconsistent cycle performance and their structural instability is hindering their practical applications in rechargeable batteries. Additionally, Tin by itself is expensive compared to carbon which is in abundance and can be derived from either petroleum based products or as a derivative of many polymers.

\subsection{Si/Carbon composite nanofibers}


Silicon is considered as a good candidate to use as anode material in lithium-ion batteries due to its high specific capacity and low discharge potentials. A fully lithiated $\mathrm{Si}-\mathrm{Li}$ (i.e. $\mathrm{Li}_{21} \mathrm{Si}$ ) alloy has a large theoretical $\sim 400 \mathrm{mAhg}^{-1}$ which is 10 time greater than that of the graphite. However, the many associated problems of the LiSi-based cells such as; large irreversible capacity at room temperature $[2,6,7,152-154]$ and poor cyclability $[3,155]$ that is often attributed to low electronic conductivity and the large volume change (>300\%) during lithium insertion/de-insertion process. This volume change impacts negatively on the Si crystal structure, inducing stresses in Si lattice and thus leading to cracks formation and pulverization of the Si particles. Various approaches have been developed to minimize the drawbacks of LiSi anodes, these include better morphological design [156], synthesis of single-phase LiSi by highly energetic ball-milling [29] using impregnating Silicon nanoparticle assemblies in templated carbon-bridged oriented graphene[157], Coating copper on a nano columnar silicon anodes [158], and creating nanosheets of silicon-based electrode by topochemical reaction synthesis [159].These approaches and techniques help mitigate the drastic reduction of the LiSi anode capacity, but are not sufficient to maintain a good capacity retention and cycle life [160, $161]$.

\subsection{1 $\mathrm{Si} / \mathrm{C}$ composite nanofiber anode}

Si/CNFs binary composite electrodes $[6,162,163]$ from nanostructured metal/ oxide namely: $\mathrm{Ge}, \mathrm{SnO}_{2}, \mathrm{MnOx}$, iron oxides, and $\mathrm{TiO}_{2}[22,164,165]$ have been developed to improve the electrochemical performances of LiSi electrode. In the Si/metal binary alloys composites [26, 27, 165-170], the metal/metal oxides act as the unlithiated part of the composite alloy thereby

forming a framework that prevents the pulverization of the Si particles[6], improve stability and 
electrochemical performance of the LiSi electrode. Some of these binary $\mathrm{Si} /$ metal/CNFs have been widely reported to delivered a discharge capacity of $1000 \mathrm{~mA} \mathrm{~h} \mathrm{~g}^{-1}$ over 200 cycles $[3,167$, 171-181](Fig.4). The carbon nanofiber in the matrix acts as a buffer for the volume change and improves the electronic conductivity of the electrode. $[6,7,182-186]$. The Si/CNFs nanostructures can suppress volume changes since the pores act as the structure buffer for the large volume changes during cycling, and hence help maintain the high specific capacity and cycle performance of the electrode above $1500 \mathrm{mAhg}^{-1}$ over several cycles $[3,7,22,163,167]$. Although nanostructured Si/CNFs anodes and their composites have improved electrochemical performance, several problems need to be solved including; dispersion of Si nanoparticles in the carbon matrix, high production cost usually associated with the price of silicon as the based material. More work needs to be done to address these issues.

\subsection{Ferriferous oxide /Carbon nanofibers anode}

Ferriferous oxides $\left(\mathrm{Fe}_{3} \mathrm{O}_{4}\right) / \mathrm{CNFs}$ are the other class of promising alternative materials that have been widely investigated as anodes [9, 25, 33, 150, 187-192]. Ferriferous oxides typically have higher theoretical specific capacity of about $924 \mathrm{mAh} / \mathrm{g}$, relatively inexpensive and environment friendly (non-toxic) [193-195]. However, similar to $\mathrm{Si}$, $\mathrm{Ti}$, and $\mathrm{Sn}$, the bare $\mathrm{Fe}_{2} \mathrm{O}_{3}$ and $\mathrm{Fe}_{3} \mathrm{O}_{4}$ have low conductivity and prone to structural pulverization and loss of electrical connection due to large volume changes during lithiation/delithiation, resulting in the poor rapid capacity retention during long-term cycling $[9,21,33,188,193]$. To overcome these drawbacks of $\mathrm{Fe}_{3} \mathrm{O}_{4}$ anodes, carbon nanofibers have been employed as matrix to prepare $\mathrm{Fe}_{3} \mathrm{O}_{4} / \mathrm{CNFs}$ composites. These $\mathrm{Fe}_{3} \mathrm{O}_{4} / \mathrm{CNFs}$ composites have improved electrochemical properties (Figure 4 and Figure 5.) due to the excellent electrical conductivity of the carbon nanofibers $[33,189,192,196]$. The 
structure of the $\mathrm{Fe}_{3} \mathrm{O}_{4} / \mathrm{CNFs}$, which are either honey-comb like carbon core and Fe shell or hollow [150, 197, 198], 3D nano-Fe3 $\mathrm{O}_{4}$,[191], or hollow $\alpha-\mathrm{LiFeO}_{2}$ [196], as shown in Figure 6.

These ferriferous structure gives the composite electrode improved low temperature performance largely on the account of the fast electron kinetics $[33,189]$ and the stability of the porous CNF and its buffering effect $[191,196,198]$. Other metals like $\mathrm{Mg}, \mathrm{Ni}$, and $\mathrm{Zn}[9,21,190,197]$ have been used as binary alloy with Ferriferous oxides along with CNFs ostensible to improve the electrochemical performance of the composite electrode. Typically the specific capacity for these binary composites are in the range of $500 \mathrm{mAhg}^{-1}$ to $700 \mathrm{mAhg}^{-1}$, which is not essentially better than those reported for $\mathrm{Fe}_{3} \mathrm{O}_{4} / \mathrm{CNFs}$ composite anodes (Fig.7), that have capacities 500 $\mathrm{mAhg}^{-1}-1225 \mathrm{mAhg}^{-1}$ even $[25,150,188,193,194]$ at higher current densities (i.e. $\left.1 \mathrm{~A} / \mathrm{g}\right)[188$, 191, 192, 196, 198], as shown in Figure 5. These metals in the binary alloy of the ferriferous also acts as a buffer layer that accommodates the large volume changes and reduced polarization [21, 190, 197] and ostensibly enhancing the kinetics and mass transfer at the electrode interface. The major challenge with the use of these ferriferous oxide electrode is how to simultaneously design and fabricate composites of $\mathrm{Fe}_{2} \mathrm{O}_{3}$ combined with CNFs. An improved fabrication technique is highly desirable since these class of alternative anode electrode are highly desired, especially for low temperature performance.

\section{Lithium metal oxide-CNFs cathode materials}

Electrospinning has been extensively used to produce nanofiber composite cathodes from different precursors such as spinel structured materials; $\mathrm{LiMn}_{2} \mathrm{O}_{4}, \mathrm{LiMPO}_{4}$ [199-201], $\mathrm{LiFePO}_{4}$ and Vanadium oxide layered compounds [202-204]. Although $\mathrm{LiMn}_{2} \mathrm{O}_{4}$ is inexpensive and safer than $\mathrm{LiCoO}_{2}$, it has a lower capacity as compared to other cathode materials that form $\alpha-\mathrm{NaFeO}_{2}$ 


\subsection{Composite nanofibers for Li/S battery cathode}

Lithium-sulfur batteries have attracted much attention and are considered as good candidates for alternative energy storage systems, largely on account of their ultra-high capacity, high theoretical specific power and energy density, easiness in handling and processing, and environmentally benign [216-223]. A Li-S battery consists of a $\mathrm{Li}$ metal anode, an organic electrolyte and a sulfur composite cathode (porous), wherein $\mathrm{S}$ (existing as $\mathrm{S}_{8}$ ) undergoes a series 

atoms $[216,217]$. The application of composite nanofibers have been investigated severally as an alternative means to improve the microstructure of the cathode electrode in $\mathrm{Li} / \mathrm{S}$ batteries. The advantage of using these carbon nanofibers with sulfur as cathode for $\mathrm{Li} / \mathrm{S}$ stem from their unique structure; porous/ hollow structures, and high specific surface area. These properties of the carbon nanofiber-sulfur based cathodes form ideal inter wound reservoir-like matrices that accommodate active sulfur $[123,153,224-240]$, while the porous structure ideally confine/trap the active sulfur and its soluble polysulfides, which can greatly reduce the shuttle effect. In addition, the carbon nanofibers improve the mechanical/ structural integrity of the composite electrode as well as the conductivity, $[232,233,238]$ that further enhances electrons/ $\mathrm{Li}^{+}$transfer and improves sulfur utilization in Li-S batteries [123, 153, 224-240] and by extension, improves the batteries electrochemical performance. The challenge however, on the use of these carbon nanofiber-sulfur-based cathodes in Li-S batteries is the inconsistency of the fiber surface area, particularly those produced by electrospinning [225, 226, 241, 242]. A relatively small surface area and a large pore volume size can lead to sulfur being exposed outside the porous structure, which can cause serious polysulfide dissolutions at prolonged battery cycling. Additionally, notwithstanding the fact that the microstructure of these carbon nanofibers provide porous / robust conductive networks, compared to graphite ( 10 micron in particle size), their surface area and pore volumes are much lower, which can limited the amount sulfur loading in the electrode. To countenance these challenges, several morphologies and electrode architectures have been designed including hollow carbon nanofiber-encapsulated sulfur[243], amphiphilic surface modification of hollow carbon nanofibers[244], highly mineralized chitin-protein fibers as biotemplates [245], bimodal mesoporous carbon nanofibers[246], impregnation of 


\subsection{Composite nanofibers for Li-air battery cathodes}

There are very few publications that explore the use of composite nanofibers as cathode material for Li-air batteries. The most common Li-air cathode material designed with carbon is $\mathrm{Co}_{3} \mathrm{O}_{4}$ [227, 259, 260] and few reports on $\mathrm{RuO}_{2} / \mathrm{CNFs}, \alpha \mathrm{MnO}_{2} / \mathrm{CNFs}[15,261-265]$. The motivation for the use of carbon nanofibers as against carbon has been the higher surface area as well as the higher pores volume that carbon nanofibers present [266],[15]. The porosity and 3-phase 
structure of air-cathode is one key and critical determining factor for the Li-air battery electrochemical performance (Fig. 11). The higher pore volume and surface area of a typical composite NFs Li-Air cathode, increase the contact area of the electrode/electrolyte interface while the pores provides a high diffusion path for both ions and oxygen necessary for the electrochemical reaction to form species such as $\mathrm{Li}_{2} \mathrm{O}_{2}$ and $\mathrm{Li}_{2} \mathrm{O}[259,262,264,265]$. These composite nanofiber cathodes record an impressive electrochemical performance over several cycles far better than the commercial $\mathrm{RuO}_{2}, \mathrm{Co}_{3} \mathrm{O}_{4}$, and $\alpha \mathrm{MnO}_{2} \mathrm{Li}$-Air cathode [15, 260-264, 267] as shown in a typical electrochemical performance plots of composite CNFs electrode for Li-Air battery in Figure 12. The downside, however of the open structure of the carbon nanofibers tends to decrease the conductivity due to occasional discontinuity in the electrical path. This challenge, notwithstanding, the pore structure provides room for the precipitation of insoluble $\mathrm{Li}_{2} \mathrm{O}_{2}$ species and insulating it from further access of reactants products such as $\mathrm{O}_{2}$ and $\mathrm{Li}^{+}[259,260]$. The high capacity of the Li-Air batteries chemistry has been established to directly depend on the presence and amount $\mathrm{Li}_{2} \mathrm{O}_{2}$ in the cathode structure [227]. Nanofibers as cathode materials seem to be in its infancy and it expected to see a growing interest in the not distance future. Nanofibers and composite nanofibers mainly prepared by electrospinning have been also used in sodium ion batteries as cathodes and separators. The discussion of these NFs is beyond the scope of this review and we refer the reader to reference [13] for more details on the structure and performance of these composite NFs.

\section{Polymeric Nanofiber Separators}

The commonly used separators in lithium-ion batteries are the microporous membrane separators made from , polypropylene, polyethylene, polyvinylidene difluoride (PVdF) or PVdF-coated 
microporous polyolefin separators [268-270]. Several companies such as Celgard, Asahi, Toray, Entek Membrane, Ube industries, DSM, etc. have been designed and developed commercial separators for the over \$4billion lithium ion batteries market [271], these mostly consist of polymer materials such as polyolefin microporous membranes developed by Celgard, DSM, and Asahi and a tri-layer of polypropylene/polyethylene/polypropylene from Celgard and Ube industries. High performance separators must have 1) more porosity, 2) safer to puncture and shorts, 3) higher melt stability, 4) thinner structure to allow for more active material, 5) very thin layer to allow for composite structures of ceramic coatings, 6) very thin and porous nonwoven to be filled with polymer electrolyte, 7) High thermal stability, and 8) lower cost for used in hybrid vehicles automobile [268, 270, 271]. However, several studies [79, 270, 272-276] have pointed to these polymer-based battery separators to have less impressive key performance indices such as: high interface resistance, low thermal stability, and low electrolyte uptake. The severe thermal shrinkage of polyolefin separators can cause serious internal electrical short circuit leading to a fire disaster or battery explosion when the cells are exposed to abnormal operating conditions. Some battery separator producers such as Celgard Inc., have made several improvement to its polypropylene (PP) mono layer polymer separator by designing a three layer separator comprising of the polypropylene/ polyethylene / polypropylene ( i.e. PP/PE/PP) thereby improving the deficiency of its mono layer separators Celgard [35, 36, 38, 49, 52, 68, 77]. Nonetheless, the performance of the non-woven nanofibers separators are gradually being considered better alternatives.

\subsection{Nonwoven fibrous polymer separators}


Lithium ion battery separators most often are classified into three categories; microporous membranes, non-woven mats and inorganic composite membrane separators. In all, they are usually characterized by their thinness, excellent thermal stability and the high porosity that gives them their ion transport characteristics [37, 54-57, 61-63, 277-284]. The increasing vulnerability of the lithium battery to thermal runaway requires a separator with greater mechanical integrity above $130^{\circ} \mathrm{C}[285,286]$ to provide a greater margin of safety to the battery. The nonwoven nanofiber separator membrane fibers have shown to be much better stability in the redox environment compared to other polymeric based separators[287] (Fig. 13). The nonwoven category such as cellulosic fibers, $\mathrm{PVdF}$, ceramic fibers, nanocomposite polymer have been extensively studied. The PVdF itself has been extensively used as a polymer electrolyte [288-293] by virtue of its appealing electrochemical properties. Generally, the PVdF based polymer electrolytes are anodically stable in the redox environment in the lithium ion battery due partly to the strong electron-withdrawing of the C-F functional groups on the polymer backbone [294, 295]. The PVdF category of nonwoven nanofiber separators show improved electrochemical performance relative to the commonly used polypropylene/ polyethylene (i.e. PP/PE) polymeric separators (Fig.14). In the same vein, the cellulosic fibers have never been used successfully in commercial (mostly in laboratory cells) lithium batteries due to their hygroscopic nature of cellulosic papers and films, their tendency to degrade in contact with lithium metal, and their susceptibility to pinhole formation at thicknesses of about $100 \mu \mathrm{m}[54$, 65, 277-279]. This notwithstanding, the cellulosic separators still maintain some level of research interest due largely to the various morphologies of the cellulose membrane ( Fig.15) that offer stability at higher temperatures compared to separators made of polyolefin or can be coupled 
with the other polymeric separator materials with low melting properties as a polymeric laminate material [277, 278].

The non-woven fibrous mats, despite their remarkable properties, have less mechanical strength compared to their PP counterparts[296] and are also yet to be used in commercial lithium ion batteries as separators. The drawback in their application is often attributed to their open structure and their rough surface which cannot effectively prevent micro short circuits and dendrites penetration [278], but mainly used in other battery chemistries such as alkaline batteries such as nickel-cadmium and nickel-metal-hydride batteries. In lithium ion batteries, these non-woven fiber mats are widely used as supporting framework architecture to make gel power electrolyte due largely to their high porosity and large pore size $[35,52]$ as shown in Figure 15 and 16.

\subsection{Improvement Trends}

\subsubsection{Coating separators with ceramic particles}

As many researchers identified the short coming of these microporous polymer separators, has paved the way for many research efforts geared towards improving especially the mono layer PP separator for lithium ion batteries, while very viable alternative separators materials are sought. Ceramic coatings such as $\mathrm{TiO}_{2}$ are deposited on the Tri-layer polymeric separator [270], $\mathrm{Al}_{2} \mathrm{O}_{3}$ and hydrophilic poly(lithium-4-styrenesulfonate) onto the porous polyethylene membrane [276], and $\mathrm{SiO}_{2}$ coating on polyethylene $[297,298]$. These ceramic coating on the polymeric separator not only afford the separator its dimensional stability, but they also improve the porous structure of the separator that allow higher ion transport to improve ionic conductivity and low inner resistance [54, 299]. 


\subsubsection{Coating separators with polymer nanofiber (NFs)}

The mono layer polypropylene separator has also been improved using various polymer coatings such as polymers and polymer NFs coatings. Among these polymers include the use of poly(vinylidenefluoride-co-hexafluoropropylene), and poly(ethyleneglycol) dimethacrylate (PVDF-HFP) to modify the monolayer polypropylene separator (Fig.17.) [35, 36, 49, 52, 273, 299], ethylcellulose and a thermally stable and renewable biomass materials also used on the trilayer ( i.e. PP/PE/PP) polymer separator [65]. These coated polymers improve the Celgard mono layer PP separator qualities by acting as pores multipliers, improving the close niche nanofiberous structure and thus significantly reducing the thermal shrinkage of the separator, and improving the electrolyte uptake and its adhesion to the electrode[47, 300, 301]. To improve both the thermal, ionic conductivity, and interfacial properties with lithium electrodes of these nonwoven fibrous separator mat, inert ceramic oxides fillers such as silicon dioxide $\left(\mathrm{SiO}_{2}\right)$, titanium dioxide $\left(\mathrm{TiO}_{2}\right)$ and alumina $\left(\mathrm{Al}_{2} \mathrm{O}_{3}\right)$ are generally incorporated into the base polymer matrix [54, 298, 302-306]. The enhancement in the electrochemical properties of these nanocomposite separators is generally attributed to the decrease of the polymer crystallinity in the presence of these nanoparticles and the interactions of the ceramic particles with the Lewisacids in the electrolyte[279]. However, they are often not suitable for high-rate performance and cycle performance class of lithium ion batteries due to their nano-porous structure (Fig. 15\&16) and the flow property of gel polymer electrolytes at high temperatures [305, 307].

For lithium-ion battery applications, microporous polyolefin membranes, and non-woven composite membrane separators should have the ability to absorb and retain electrolyte in order to transport lithium ions between the anode and cathode. Unique techniques such as selfassembly and atomic layer deposition have employed to prepare advanced separators from 
polymeric materials for used in lithium-ion batteries. Inadvertently, all these techniques have their drawbacks, hence additional work is needed for the continual development of new separator structures to meet the high performance and energy density of advanced secondary batteries. More details on the discussion of these techniques and methods reported on the current challenges and prospects of electrospun nanofibers used in advanced secondary batteries can be found in these two references $[308,309]$

\section{Conclusions}

The development of improved energy storage materials has often been a challenge in meeting the current and future energy requirement. Re-designing the architecture of these materials into nanofiber from various techniques have received attention. Various lithium batteries components; electrodes and separators in particular have been produced with nanofiber structure that showed remarkable electrochemical performance. The findings from the various CNFs electrode and separator point to a revolution in the energy materials with higher energy density and longer cycle life. The major challenges that confront this new frontier is the seemingly lack of scalable method among the various techniques used to make these nanofibers. Most of these methods are lab scale in nature, thus making the commercialization of this new developed materials an illusion. However, there could be an end in sight for this problem with the coming on stream of the forcespinning and electrospinning method with the capability to mass produce nanofibers with good fiber yield from variety of materials. The labyrinth structure of the nanofibers also pose new challenge specially for separator materials as pin-hole size in the 
materials could be a major headache as these can lead to dendrite penetration leading to an old problem of battery thermal runaway from electrode short circuits. These drawbacks notwithstanding, the nanofiber revolution hold a great promise to the energy storage industry.

\author{
Acknowledgment \\ This research is supported by NSF PREM award DMR-1523577: UTRGV-UMN Partnership for \\ Fostering Innovation by Bridging Excellence in Research and Student Success. We thank also \\ the funding support from UT system (STARS Program)- A Startup funding to M. Alcoutlabi.
}

\title{
Figure Caption:
}

Figure 1a: A pictorial view of the Forcespinning machine and a schematic drawing of a typical setup inside the machine showing the collectors, the spinneret and the substrate/fan assembly for fiber production.

Figure 1b: A schematic drawing of nanofiber making process using electrospinning. Reproduced with permission from Journal of Materials Science [51].

Figure 2: A typical Pictorial view of the As-forcespun Sn/PAN precursor nanofiber (a) and the carbonized $\mathrm{Sn} / \mathrm{C}$ at $800^{\circ} \mathrm{C}$ for $3 \mathrm{hrs}(\mathrm{b})$.

Figure 3: SEM micrographs showing the morphology of the baseline as forcespun PAN fibers (a) and the carbinized PAN CNFs (b), the forcespun Sn/PAN fibers(c) and the Carbonized Sn/C nanofiber (d) nanofibers showing pores on the fibers strands.

Figure 4: A plot showing typical cycling performance of the base CNFs electrode, Sn/CNFs composite electrode and $\mathrm{Si} / \mathrm{CNF}$ composite electrode cells. Si/CNFs anodes show capacity fading because of the volume change.

Figure 5: Rate performance of $\mathrm{Sn} / \mathrm{C}, \mathrm{SnO} 2 / \mathrm{C}$, and $\mathrm{Fe}_{2} \mathrm{O}_{3} / \mathrm{C}$ composite electrode cycled between $0.01-3.0 \mathrm{~V}$ vs $\mathrm{Li} / \mathrm{Li}^{+}$

Figure 6: SEM micrograph of a typical (a) $\mathrm{Fe}_{3} \mathrm{O}_{4} / \mathrm{PAN} / \mathrm{PS}$ precursor fibers and cross-section of the nanofiber showing the pore structure and hollowness of the finished of $\mathrm{Fe}_{3} \mathrm{O}_{4} / \mathrm{CNFs}$.[182] Reproduced with permission from Carbon. 
Figure 7: A plot showing typical cycling performance of the ferriferous oxide/carbon nanofibers composite electrode and cathode materials cells.

Figure 8: SEM images (a) as-spun $\mathrm{LiFePO}_{4}$ precursor/PAN nanofibers (b) ASL-PAN after $300^{\circ} \mathrm{C}$ heat treatment, (c) $\mathrm{LiFePO}_{4} / \mathrm{C}$ composite nanofibers after calcination at $800^{\circ} \mathrm{C}$, and (d) high magnification of the region marked with a square in (c)[214]. Reproduced with permission from the Int. J. Electrochem. Sci.

Figure 9: SEM images of hollow carbon nanofiber-Sulfur composite electrode (a,b) [222], Nitrogen doped carbon nanofiber web/sulfur composite electrode (c)[247] and CNFs with sulfur coating(d) [230]. Reproduced with permission from Power Sources, Electrochimica Acta and Nano Lett.

Figure 10: A typical plots showing the effect of CNFs/S microstructure [247] on cell performance (a) and the rate capability of these of the S-CNF nanocomposite with (G-S-CNFs) composite electrodes [230] (b). Reproduced with permission from Nano. Lett. and Electrochmica Acta .

Figure 11: Microstructure of mesoporous silica coated carbon nanofibers $(a, b)$ [15] and mesoporous flower-like cobalt oxide/carbon nanofiber composites with shell-core structure (c,d) [264]composite electrodes for Li-Air batteries. Reproduced with permission from Applied Surf. Sci. and Carbon

Figure 12: A typical electrochemical discharge/charge curves at a current density of $100 \mathrm{~mA} \mathrm{g-1}$ (a) and rate performance at varying current densities (b) from $200 \mathrm{~mA} \mathrm{~g}-1$ to $1000 \mathrm{~mA} \mathrm{g-1} \mathrm{of}$ CNFs/ RuO2 composite Li-Air electrode[4]. Reproduced with permission from J.Power Sources

Figure 13: A plots showing a comparison of the stability of the separator in the redox environment from the cellulose, PAN nanofiber membrane and some polymeric materials like PP and tri-layer of PP/PE.

Figure 14: A plot showing typical cycling performance of the base Cellulose, PAN, PVdF and modified PP/PE coated separators for use in lithium ion batteries.

Figure 15: Various morphologies of nanofiber cellulose membrane separator mats for use in the lithium ion batteries.

Figure 16: A typical SEM micrographs showing fibrous separator made from PAN membrane showing a fiber average diameter of $<2 \mu \mathrm{m}$ with fibers with a lot of pores on the fiber strands.

Figure 17: SEM images of uncoated (a, c) Monolayer polypropylene (PP) separator, (b, d) Monolayer PP coated with PVDF-co-CTFE and PVDF-co-HFP. Reproduced with permission from Journal of Solid State Electrochemistry [49] 


\section{References}

1. Fang, S., L. Shen, Z. Tong, H. Zheng, F. Zhang, and X. Zhang, Si nanoparticles encapsulated in elastic hollow carbon fibres for Li-ion battery anodes with high structural stability. Nanoscale, 2015. 7(16): p. 7409-7414.10.1039/c5nr00132c

2. Feng, J., Z. Zhang, L. Ci, W. Zhai, Q. Ai, and S. Xiong, Chemical dealloying synthesis of porous silicon anchored by in situ generated graphene sheets as anode material for lithium-ion batteries. Journal of Power Sources, 2015. 287: p. 177-183.10.1016/j.jpowsour.2015.04.051

3. Gomez-Camer, J.L., H. Thuv, and P. Novak, Electrochemical study of Si/C composites with particulate and fibrous morphology as negative electrodes for lithium-ion batteries. Journal of Power Sources, 2015. 294: p. 128-135.10.1016/j.jpowsour.2015.06.067

4. Guo, Z., D. Zhou, H. Liu, X. Dong, S. Yuan, A. Yu, Y. Wang, and Y. Xia, Synthesis of ruthenium oxide coated ordered mesoporous carbon nanofiber arrays as a catalyst for lithium oxygen battery. Journal of Power Sources, 2015. 276: p. 181-188.10.1016/j.jpowsour.2014.11.145

5. Jiang, H., Y. Ge, K. Fu, Y. Lu, C. Chen, J. Zhu, M. Dirican, and X. Zhang, Centrifugally-spun tincontaining carbon nanofibers as anode material for lithium-ion batteries. Journal of Materials Science, 2015. 50(3): p. 1094-1102.10.1007/s10853-014-8666-5

6. Kim, H., X. Huang, Z. Wen, S. Cui, X. Guo, and J. Chen, Novel hybrid Si film/carbon nanofibers as anode materials in lithium-ion batteries. Journal of Materials Chemistry A, 2015. 3(5): p. 19471952.10.1039/c4ta05804f

7. Kim, H., Y. Son, C. Park, M.-J. Lee, M. Hong, J. Kim, M. Lee, J. Cho, and H.C. Choi, Germanium Silicon Alloy Anode Material Capable of Tunable Overpotential by Nanoscale Si Segregation. Nano letters, 2015. 15(6): p. 4135-4142.10.1021/acs.nanolett.5b01257

8. Kim, Y.-J., H. Lee, D.J. Lee, J.-K. Park, and H.-T. Kim, Reduction of Charge and Discharge Polarization by Cobalt Nanoparticles-Embedded Carbon Nanofibers for Li-O2 Batteries. ChemSusChem, 2015. 8(15): p. 2422-2422.10.1002/cssc.201500924

9. Kong, J., X. Yao, Y. Wei, C. Zhao, J.M. Ang, and X. Lu, Polydopamine-derived porous nanofibers as host of ZnFe2O4 nanoneedles: towards high-performance anodes for lithium-ion batteries. Rsc Advances, 2015. 5(18): p. 13315-13323.10.1039/c4ra16460a

10. Lee, H.-G., A.-I. Gopalan, G. Sai-Anand, B.-C. Lee, S.-W. Kang, and K.-P. Lee, Facile synthesis of functionalized graphene-palladium nanoparticle incorporated multicomponent TiO2 composite nanofibers. Materials Chemistry and Physics, 2015. 154: p. 125-

136.10.1016/j.matchemphys.2015.01.055

11. Park, S.H. and W.J. Lee, Coaxial carbon nanofiber/NiO core-shell nanocables as anodes for lithium ion batteries. Rsc Advances, 2015. 5(30): p. 23548-23555.10.1039/c4ra15147j

12. Wu, Y.Z., C.V.R. Bobba, and S. Ramakrishna, Research and Application of Carbon Nanofiber and Nanocomposites via Electrospinning Technique in Energy Conversion Systems. Current Organic Chemistry, 2013. 17(13): p. 1411-1423

13. Wang, H.G., S. Yuan, D.L. Ma, X.B. Zhang, and J.M. Yan, Electrospun materials for lithium and sodium rechargeable batteries: from structure evolution to electrochemical performance. Energy \& Environmental Science, 2015. 8(6): p. 1660-1681.10.1039/c4ee03912b

14. Luo, L., Y.Q. Fei, K. Chen, D.W. Li, X. Wang, Q.Q. Wang, Q.F. Wei, and H. Qiao, Facile synthesis of one-dimensional zinc vanadate nanofibers for high lithium storage anode material. Journal of Alloys and Compounds, 2015. 649: p. 1019-1024.10.1016/j.jallcom.2015.07.265

15. Song, M.J. and M.W. Shin, Fabrication and characterization of carbon nanofiber@mesoporous carbon core-shell composite for the Li-air battery. Applied Surface Science, 2014. 320: p. 435440.http://dx.doi.org/10.1016/j.apsusc.2014.09.100 
16. Gao, D.W., L.L. Wang, C.X. Wang, and Q.F. Wei, Electrospinning of Porous Carbon Nanocomposites for Supercapacitor. Fibers and Polymers, 2015. 16(2): p. 421425.10.1007/s12221-015-0421-2

17. He, Y.T., L.X. Wang, D.Z. Jia, and H.Y. Zhao, Coal-based Carbon Nanofibers Prepared by Electrospinning for Supercapacitor. Chemical Journal of Chinese Universities-Chinese, 2015. 36(1): p. 157-164.10.7503/cjcu20140455

18. Xiong, X., W. Luo, X. Hu, C. Chen, L. Qie, D. Hou, and Y. Huang, Flexible Membranes of MoS2/C Nanofibers by Electrospinning as Binder-Free Anodes for High-Performance Sodium-Ion Batteries. Scientific Reports, 2015. 5.925410.1038/srep09254

19. Aravindan, V., J. Sundaramurthy, P.S. Kumar, Y.-S. Lee, S. Ramakrishna, and S. Madhavi, Electrospun nanofibers: A prospective electro-active material for constructing high performance Li-ion batteries. Chemical Communications, 2015. 51(12): p. 2225-2234.10.1039/c4cc07824a

20. Koo, J.B., B.Y. Jang, S.S. Kim, K.S. Han, D.H. Jung, and S.H. Yoon, Physical mixtures of Si nanoparticles and carbon nanofibers as anode materials for lithium-ion batteries. Japanese Journal of Applied Physics, 2015. 54(8).08500110.7567/jjap.54.085001

21. Luo, L., R. Cui, K. Liu, H. Qiao, and Q. Wei, Electrospun preparation and lithium storage properties of NiFe2O4 nanofibers. Ionics, 2015. 21(3): p. 687-694.10.1007/s11581-014-1213-1

22. McCormac, K., I. Byrd, R. Brannen, B. Seymour, J. Li, and J. Wu, Preparation of porous Si and TiO2 nanofibres using a sulphur-templating method for lithium storage. Physica Status Solidi aApplications and Materials Science, 2015. 212(4): p. 877-881.10.1002/pssa.201431834

23. Peng, Y.-T. and C.-T. Lo, Effect of Microstructure and Morphology of Electrospun Ultra-Small Carbon Nanofibers on Anode Performances for Lithium Ion Batteries. Journal of the Electrochemical Society, 2015. 162(6): p. A1085-A1093.10.1149/2.0061507jes

24. Shi, X., W. Zhou, D. Ma, Q. Ma, D. Bridges, Y. Ma, and A. Hu, Electrospinning of Nanofibers and Their Applications for Energy Devices. Journal of Nanomaterials, 2015.14071610.1155/2015/140716

25. Cho, J.S., Y.J. Hong, and Y.C. Kang, Design and Synthesis of Bubble-Nanorod-Structured Fe2O3Carbon Nanofibers as Advanced Anode Material for Li-lon Batteries. Acs Nano, 2015. 9(4): p. 4026-4035.10.1021/acsnano.5b00088

26. Jing, S., H. Jiang, Y. Hu, J. Shen, and C. Li, Face-to-Face Contact and Open-Void Coinvolved Si/C Nanohybrids Lithium-Ion Battery Anodes with Extremely Long Cycle Life. Advanced Functional Materials, 2015. 25(33): p. 5395-5401.10.1002/adfm.201502330

27. Zhang, J., Y. Liang, Q. Zhou, Y. Peng, and H. Yang, Enhancing electrochemical properties of silicongraphite anodes by the introduction of cobalt for lithium-ion batteries. Journal of Power Sources, 2015. 290: p. 71-79.10.1016/j.jpowsour.2015.05.003

28. Li, B., S. Yang, S. Li, B. Wang, and J. Liu, From Commercial Sponge Toward 3D Graphene-Silicon Networks for Superior Lithium Storage. Advanced Energy Materials, 2015. 5(15).150028910.1002/aenm.201500289

29. Tang, W.S., J.N. Chotard, and R. Janotz, Synthesis of Single-Phase LiSi by Ball-Milling: Electrochemical Behavior and Hydrogenation Properties. Journal of the Electrochemical Society, 2013. 160(8): p. A1232-A1240.10.1149/2.089308jes

30. Xu, S., K. Kan, Y. Yang, C. Jiang, J. Gao, L. Jing, P. Shen, L. Li, and K. Shi, Enhanced NH3 gas sensing performance based on electrospun alkaline-earth metals composited SnO2 nanofibers. Journal of Alloys and Compounds, 2015. 618: p. 240-247.10.1016/j.jallcom.2014.08.153 
31. Kumar, P.S., J. Sundaramurthy, S. Sundarrajan, V.J. Babu, G. Singh, S.I. Allakhverdiev, and S. Ramakrishna, Hierarchical electrospun nanofibers for energy harvesting, production and environmental remediation. Energy \& Environmental Science, 2014. 7(10): p. 31923222.10.1039/c4ee00612g

32. Lee, J.-H., A. Katoch, S.-W. Choi, J.-H. Kim, H.W. Kim, and S.S. Kim, Extraordinary Improvement of Gas-Sensing Performances in SnO2 Nanofibers Due to Creation of Local p-n Heterojunctions by Loading Reduced Graphene Oxide Nanosheets. Acs Applied Materials \& Interfaces, 2015. 7(5): p. 3101-3109.10.1021/am5071656

33. Li, M., Y. Xiong, X. Liu, X. Bo, Y. Zhang, C. Han, and L. Guo, Facile synthesis of electrospun $\mathrm{MFe} 2 \mathrm{O} 4(\mathrm{M}=\mathrm{Co}, \mathrm{Ni}, \mathrm{Cu}, \mathrm{Mn}$ ) spinel nanofibers with excellent electrocatalytic properties for oxygen evolution and hydrogen peroxide reduction. Nanoscale, 2015. 7(19): p. 89208930.10.1039/c4nr07243j

34. Garcia, E., Q. Li, X. Sun, K. Lozano, and Y. Mao, TiO2 Fibers: Tunable Polymorphic Phase Transformation and Electrochemical Properties. Journal of Nanoscience and Nanotechnology, 2015. 15(5): p. 3750-3756.10.1166/jnn.2015.9545

35. Lee, H., M. Alcoutlabi, J.V. Watson, and X.W. Zhang, Electrospun nanofiber-coated separator membranes for lithium-ion rechargeable batteries. Journal of Applied Polymer Science, 2013. 129(4): p. 1939-1951.10.1002/app.38894

36. Lee, H., M. Alcoutlabi, J.V. Watson, and X.W. Zhang, Polyvinylidene fluoride-cochlorotrifluoroethylene and polyvinylidene fluoride-co-hexafluoropropylene nanofiber-coated polypropylene microporous battery separator membranes. Journal of Polymer Science Part BPolymer Physics, 2013. 51(5): p. 349-357.10.1002/polb.23216

37. Nunes-Pereira, J., C.M. Costa, R. Leones, M.M. Silva, and S. Lanceros-Mendez, Li-ion battery separator membranes based on poly(vinylidene fluoride-trifluoroethylene)/carbon nanotube composites. Solid State lonics, 2013. 249: p. 63-71.DOI 10.1016/j.ssi.2013.07.021

38. Weng, B.C., F.H. Xu, M. Alcoutlabi, Y.B. Mao, and K. Lozano, Fibrous cellulose membrane mass produced via forcespinning(A $(R))$ for lithium-ion battery separators. Cellulose, 2015. 22(2): $p$. 1311-1320.10.1007/s10570-015-0564-8

39. Weng, B.C., F.H. Xu, and K. Lozano, Mass Production of Carbon Nanotube-Reinforced Polyacrylonitrile Fine Composite Fibers. Journal of Applied Polymer Science, 2014. 131(11).Artn 40302Doi 10.1002/App.40302

40. Weitz, R.T., L. Harnau, S. Rauschenbach, M. Burghard, and K. Kern, Polymer nanofibers via nozzle-free centrifugal spinning. Nano Letters, 2008. 8(4): p. 1187-1191.10.1021/nl080124q

41. Loordhuswamy, A.M., V.R. Krishnaswamy, P.S. Korrapati, S. Thinakaran, and G.D.V. Rengaswami, Fabrication of highly aligned fibrous scaffolds for tissue regeneration by centrifugal spinning technology. Materials Science \& Engineering C-Materials for Biological Applications, 2014. 42: p. 799-807.10.1016/j.msec.2014.06.011

42. Xu, H.Z., H.H. Chen, X.L. Li, C. Liu, and B. Yang, A Comparative Study of Jet Formation in Nozzleand Nozzle-Less Centrifugal Spinning Systems. Journal of Polymer Science Part B-Polymer Physics, 2014. 52(23): p. 1547-1559.10.1002/polb.23596

43. Badrossamay, M.R., H.A. Mcllwee, J.A. Goss, and K.K. Parker, Nanofiber Assembly by Rotary JetSpinning. Nano Letters, 2010. 10(6): p. 2257-2261.10.1021/nl101355x

44. Alcoutlabi, M. and G.B. McKenna, Effects of confinement on material behaviour at the nanometre size scale. Journal of Physics-Condensed Matter, 2005. 17(15): p. R461-R524.Doi 10.1088/0953-8984/17/15/R01 
45. Ron, L.Y. and S.P. Kotha, Centrifugal jet spinning for highly efficient and large-scale fabrication of barium titanate nanofibers. Materials Letters, 2014. 117: p. 153-157.DOI 10.1016/j.matlet.2013.11.103

46. Sarkar, K., C. Gomez, S. Zambrano, M. Ramirez, E. de Hoyos, H. Vasquez, and K. Lozano, Electrospinning to Forcespinning ${ }^{T M}$. Materials Today, 2010. 13(11): p. 1214.http://dx.doi.org/10.1016/S1369-7021(10)70199-1

47. Zhang, J.Q., S.Q. Chen, X.Q. Xie, K. Kretschmer, X.D. Huang, B. Sun, and G.X. Wang, Porous poly(vinylidene fluoride-co-hexafluoropropylene) polymer membrane with sandwich-like architecture for highly safe lithium ion batteries. Journal of Membrane Science, 2014. 472: p. 133-140.10.1016/j.memsci.2014.08.049

48. Zhang, X. and Y. Lu, Centrifugal Spinning: An Alternative Approach to Fabricate Nanofibers at High Speed and Low Cost. Polymer Reviews, 2014. 54(4): p. 677701.10.1080/15583724.2014.935858

49. Lee, H., M. Alcoutlabi, O. Toprakci, G.J. Xu, J.V. Watson, and X.W. Zhang, Preparation and characterization of electrospun nanofiber-coated membrane separators for lithium-ion batteries. Journal of Solid State Electrochemistry, 2014. 18(9): p. 2451-2458.10.1007/s10008-014-2501-4

50. Klankowski, S.A., G.P. Pandey, B.A. Cruden, J. Liu, J. Wu, R.A. Rojeski, and J. Li, Anomalous capacity increase at high-rates in lithium-ion battery anodes based on silicon-coated vertically aligned carbon nanofibers. Journal of Power Sources, 2015. 276: p. 7379.10.1016/j.jpowsour.2014.11.094

51. Alcoutlabi, M., L.W. Ji, B.K. Guo, S.L. Li, Y. Li, S. Zhang, O. Toprakci, and X.W. Zhang, Electrospun Nanofibers for Energy Storage. Aatcc Review, 2011. 11(6): p. 45-51

52. Alcoutlabi, M., H. Lee, J.V. Watson, and X.W. Zhang, Preparation and properties of nanofibercoated composite membranes as battery separators via electrospinning. Journal of Materials Science, 2013. 48(6): p. 2690-2700.10.1007/s10853-012-7064-0

53. Ji, L.W., Z. Lin, M. Alcoutlabi, and X.W. Zhang, Recent developments in nanostructured anode materials for rechargeable lithium-ion batteries. Energy \& Environmental Science, 2011. 4(8): p. 2682-2699.10.1039/c0ee00699h

54. Kim, Y.J., C.H. Ahn, M.B. Lee, and M.S. Choi, Characteristics of electrospun PVDF/SiO2 composite nanofiber membranes as polymer electrolyte. Materials Chemistry and Physics, 2011. 127(1-2): p. 137-142.DOI 10.1016/j.matchemphys.2011.01.046

55. Yanilmaz, M., Y. Lu, Y. Li, and X.W. Zhang, SiO2/polyacrylonitrile membranes via centrifugal spinning as a separator for Li-ion batteries. Journal of Power Sources, 2015. 273: p. 11141119.DOI 10.1016/j.jpowsour.2014.10.015

56. Kim, Y.J., H.S. Kim, C.H. Doh, S.H. Kim, and S.M. Lee, Technological potential and issues of polyacrylonitrile based nanofiber non-woven separator for Li-ion rechargeable batteries. Journal of Power Sources, 2013. 244: p. 196-206.DOI 10.1016/j.jpowsour.2013.01.166

57. Khan, W.S., R. Asmatulu, V. Rodriguez, and M. Ceylan, Enhancing thermal and ionic conductivities of electrospun PAN and PMMA nanofibers by graphene nanoflake additions for battery-separator applications. International Journal of Energy Research, 2014. 38(15): p. 20442051.Doi 10.1002/Er.3188

58. Lee, H., J. Yun, H. Choi, D. Kim, and H. Byun, The preparation of primary battery separator using polyamide nonwoven and nanofiber. Applied Energy Technology, Pts 1 and 2, 2013. 724-725: p. 1079-1082.DOI 10.4028/www.scientific.net/AMR.724-725.1079

59. Ren, L.Y., R. Ozisik, S.P. Kotha, and P.T. Underhill, Highly Efficient Fabrication of Polymer Nanofiber Assembly by Centrifugal Jet Spinning: Process and Characterization. Macromolecules, 2015. 48(8): p. 2593-2602.10.1021/acs.macromol.5b00292 
60. Golecki, H.M., H.Y. Yuan, C. Glavin, B. Potter, M.R. Badrossamay, J.A. Goss, M.D. Phillips, and K.K. Parker, Effect of Solvent Evaporation on Fiber Morphology in Rotary Jet Spinning. Langmuir, 2014. 30(44): p. 13369-13374.10.1021/la5023104

61. Lee, J.H., J. Manuel, H. Choi, W.H. Park, and J.-H. Ahn, Partially oxidized polyacrylonitrile nanofibrous membrane as a thermally stable separator for lithium ion batteries. Polymer, (0).http://dx.doi.org/10.1016/j.polymer.2015.04.055

62. Raghavan, P., J. Manuel, X. Zhao, D.S. Kim, J.H. Ahn, and C. Nah, Preparation and electrochemical characterization of gel polymer electrolyte based on electrospun polyacrylonitrile nonwoven membranes for lithium batteries. Journal of Power Sources, 2011. 196(16): p. 6742-6749.DOI 10.1016/j.jpowsour.2010.10.089

63. Subramania, A., N.T.K. Sundaram, A.R.S. Priya, and G.V. Kumar, Preparation of a novel composite micro-porous polymer electrolyte membrane for high performance Li-ion battery. Journal of Membrane Science, 2007. 294(1-2): p. 8-15.10.1016/j.memsci.2007.01.025

64. Zhou, X.H., L.P. Yue, J.J. Zhang, Q.S. Kong, Z.H. Liu, J.H. Yao, and G.L. Cui, A Core-Shell Structured Polysulfonamide-Based Composite Nonwoven Towards High Power Lithium Ion Battery Separator. Journal of the Electrochemical Society, 2013. 160(9): p. A1341-A1347.Doi 10.1149/2.003309jes

65. Sohn, J.Y., J.S. Im, S.J. Gwon, J.H. Choi, J. Shin, and Y.C. Nho, Preparation and characterization of a PVDF-HFP/PEGDMA-coated PE separator for lithium-ion polymer battery by electron beam irradiation. Radiation Physics and Chemistry, 2009. 78(7-8): p. 505-508.DOI 10.1016/j.radphyschem.2009.03.035

66. Sohn, J.Y., J.S. Im, J. Shin, and Y.C. Nho, PVDF-HFP/PMMA-coated PE separator for lithium ion battery. Journal of Solid State Electrochemistry, 2012. 16(2): p. 551-556.DOI 10.1007/s10008011-1379-7

67. Aravindan, V., J. Sundaramurthy, P.S. Kumar, N. Shubha, W.C. Ling, S. Ramakrishna, and S. Madhavi, A novel strategy to construct high performance lithium-ion cells using one dimensional electrospun nanofibers, electrodes and separators. Nanoscale, 2013. 5(21): p. 1063610645.10.1039/c3nr04486f

68. Liang, Y.Z., L.W. Ji, B.K. Guo, Z. Lin, Y.F. Yao, Y. Li, M. Alcoutlabi, Y.P. Qiu, and X.W. Zhang, Preparation and electrochemical characterization of ionic-conducting lithium lanthanum titanate oxide/polyacrylonitrile submicron composite fiber-based lithium-ion battery separators. Journal of Power Sources, 2011. 196(1): p. 436-441.10.1016/j.jpowsour.2010.06.088

69. Cao, C.Y., L. Tan, W.W. Liu, J.Q. Ma, and L. Li, Polydopamine coated electrospun poly(vinyldiene fluoride) nanofibrous membrane as separator for lithium-ion batteries. Journal of Power Sources, 2014. 248: p. 224-229.DOI 10.1016/j.jpowsour.2013.09.027

70. Souza, M.A., J.E. Oliveira, E.S. Medeiros, G.M. Glenn, and L.H.C. Mattoso, Controlled Release of Linalool Using Nanofibrous. Membranes of Poly(lactic acid) Obtained by Electrospinning and Solution Blow Spinning: A Comparative Study. Journal of Nanoscience and Nanotechnology, 2015. 15(8): p. 5628-5636.10.1166/jnn.2015.9692

71. Balogh, A., B. Farkas, K. Farago, A. Farkas, I. Wagner, I. Van Assche, G. Verreck, Z.K. Nagy, and G. Marosi, Melt-Blown and Electrospun Drug-Loaded Polymer Fiber Mats for Dissolution Enhancement: A Comparative Study. Journal of Pharmaceutical Sciences, 2015. 104(5): p. 17671776.10.1002/jps.24399

72. Yao, Y.F., Z. Lin, Y. Li, M. Alcoutlabi, H. Hamouda, and X.W. Zhang, Superacidic Electrospun FiberNafion Hybrid Proton Exchange Membranes. Advanced Energy Materials, 2011. 1(6): p. 11331140.10.1002/aenm.201100435 
73. Chen, W., Y. Liu, Y. Ma, J. Liu, and X. Liu, Improved performance of PVdF-HFP/PI nanofiber membrane for lithium ion battery separator prepared by a bicomponent cross-electrospinning method. Materials Letters, 2014. 133: p. 67-70.10.1016/j.matlet.2014.06.163

74. Han, L., C. Lu, P. Chen, W. Qi, and Q. Yu, The Effects OF in situ generated titanium dioxide on the mechanical and electrochemical properties of electrospun polyvinylidene fluoride seperator for lithium-ion battery. Acta Polymerica Sinica, 2012(11): p. 13191325.10.3724/sp.j.1105.2012.12053

75. Sencadas, V., J.C. Rodriguez Hernandez, C. Ribeiro, J.L. Gomez Ribelles, and S. Lanceros-Mendez, Poly(vinylidene fluoride) Electrospun Fibers for Electroactive Scaffold Aplications: Influence of the Applied Voltage on Morphology and Polymorphism, in Advances in Material Design for Regenerative Medicine, Drug Delivery and Targeting/Imaging, V.P. Shastri, et al., Editors. 2009. p. 203-208.

76. Tonurist, K., T. Thomberg, A. Jaenes, T. Romann, V. Sammelselg, and E. Lust, Polymorphic Behavior and Morphology of Electrospun Poly(vinylidene Fluoride) Separator Materials for Nonaqueous Electrolyte Based Electric Double Layer Capacitors. Batteries and Energy Technology (General Session) - 222nd Ecs Meeting/Prime 2012: In Honor of James Mcbreen, 2013. 50(45): $p$. 49-58.10.1149/05045.0049ecst

77. Weng, B.C., F.H. Xu, G. Garza, M. Alcoutlabi, A. Salinas, and K. Lozano, The Production of Carbon Nanotube Reinforced Poly(vinyl) Butyral Nanofibers by the Forcespinning (R) Method. Polymer Engineering and Science, 2015. 55(1): p. 81-87.10.1002/pen.23872

78. Weng, B.C., F.H. Xu, A. Salinas, and K. Lozano, Mass production of carbon nanotube reinforced poly(methyl methacrylate) nonwoven nanofiber mats. Carbon, 2014. 75: p. 217-226.DOI 10.1016/j.carbon.2014.03.056

79. Yanilmaz, M., C. Chen, and X.W. Zhang, Fabrication and Characterization of SiO2/PVDF Composite Nanofiber-Coated PP Nonwoven Separators for Lithium-Ion Batteries. Journal of Polymer Science Part B-Polymer Physics, 2013. 51(23): p. 1719-1726.Doi 10.1002/Polb.23387

80. Yanilmaz, M. and X.W. Zhang, Polymethylmethacrylate/Polyacrylonitrile Membranes via Centrifugal Spinning as Separator in Li-Ion Batteries. Polymers, 2015. 7(4): p. 629-643.Doi 10.3390/Polym7040629

81. Mihut, D.M., K. Lozano, and H. Foltz, Fabrication and characterization of silver- and coppercoated Nylon 6 forcespun nanofibers by thermal evaporation. Journal of Vacuum Science \& Technology A, 2014. 32(6).Artn 061401Doi 10.1116/1.4896752

82. McEachin, Z. and K. Lozano, Production and characterization of polycaprolactone nanofibers via forcespinning (TM) technology. Journal of Applied Polymer Science, 2012. 126(2): p. 473-479.Doi 10.1002/App.36843

83. Agubra, V.A., Zuniga, L. , De la Garza, D., Gallegos, L., Pokhrel, M., Alcoutlabi, M., Forcespinning: A new method for the mass production of $\mathrm{Sn} / \mathrm{C}$ composite nanofiber anodes for lithium ion batteries. Solid State Ionics, 2015. Accepted

84. Agubra, V.A., D. De la Garza, L. Gallegos, and M. Alcoutlabi, ForceSpinning of polyacrylonitrile for mass production of lithium-ion battery separators. Journal of Applied Polymer Science, 2016. 133(1).Artn 4284710.1002/App.42847

85. Sarkar, K.L.a.K., inventors Super fine Fiber Creating Spinneret and Uses Thereof, in US Patent, U.p. Office, Editor. 2009: USA

86. Padron, S., R. Patlan, J. Gutierrez, N. Santos, T. Eubanks, and K. Lozano, Production and characterization of hybrid BEH-PPV/PEO conjugated polymer nanofibers by forcespinning (TM). Journal of Applied Polymer Science, 2012. 125(5): p. 3610-3616.10.1002/app.36420

87. Hooper, J.P., Centrifugal Spinneret, in US paptent U.p. Office, Editor. 1924: USA 
88. Khamforoush, M. and T. Asgari, A Modified Electro-Centrifugal Spinning Method to Enhance the Production Rate of Highly Aligned Nanofiber. Nano, 2015. 10(2).Artn 1550016Doi 10.1142/S1793292015500162

89. Dabirian, F., S.A.H. Ravandi, and A.R. Pishevar, Investigation of Parameters Affecting PAN Nanofiber Production Using Electrical and Centrifugal Forces as a Novel Method. Current Nanoscience, 2010. 6(5): p. 545-552

90. Dabirian, F., S.A.H. Ravandi, A.R. Pishevar, and R.A. Abuzade, A comparative study of jet formation and nanofiber alignment in electrospinning and electrocentrifugal spinning systems. Journal of Electrostatics, 2011. 69(6): p. 540-546.DOI 10.1016/j.elstat.2011.07.006

91. Dabirian, F., S.A.H. Ravandi, and A.R. Pishevar, The effects of operating parameters on the fabrication of polyacrylonitrile nanofibers in electro-centrifuge spinning. Fibers and Polymers, 2013. 14(9): p. 1497-1504.DOI 10.1007/s12221-013-1497-1

92. Aravindan, V., J. Sundaramurthy, E.N. Kumar, P.S. Kumar, W.C. Ling, R. von Hagen, S. Mathur, S. Ramakrishna, and S. Madhavi, Does carbon coating really improves the electrochemical performance of electrospun SnO2 anodes? Electrochimica Acta, 2014. 121(0): p. 109115.http://dx.doi.org/10.1016/j.electacta.2013.12.141

93. Wang, W., Y. Xiao, X. Wang, B. Liu, and M. Cao, In Situ Encapsulation of Germanium Clusters in Carbon Nanofibers: High-Performance Anodes for Lithium-Ion Batteries. ChemSusChem, 2014. 7(10): p. 2914-2922.10.1002/cssc.201402304

94. Liu, X., D. Teng, T. Li, Y. Yu, X. Shao, and X. Yang, Phosphorus-doped tin oxides/carbon nanofibers webs as lithium-ion battery anodes With enhanced reversible capacity. Journal of Power Sources, 2014. 272: p. 614-621.10.1016/j.jpowsour.2014.08.084

95. Liu, Z., D. Fu, F. Liu, G. Han, C. Liu, Y. Chang, Y. Xiao, M. Li, and S. Li, Mesoporous carbon nanofibers with large cage-like pores activated by tin dioxide and their use in supercapacitor and catalyst support. Carbon, 2014. 70: p. 295-307.10.1016/j.carbon.2014.01.011

96. Simon, G.K., B. Maruyama, M.F. Durstock, D.J. Burton, and T. Goswami, Silicon-coated carbon nanofiber hierarchical nanostructures for improved lithium-ion battery anodes. Journal of Power Sources, 2011. 196(23): p. 10254-10257.http://dx.doi.org/10.1016/i.jpowsour.2011.08.058

97. Zhao, Y., X. Li, B. Yan, D. Li, S. Lawes, and X. Sun, Significant impact of 2D graphene nanosheets on large volume change tin-based anodes in lithium-ion batteries: A review. Journal of Power Sources, 2015. 274(0): p. 869-884.http://dx.doi.org/10.1016/j.jpowsour.2014.10.008

98. Alcoutlabi, M., L. Banda, S. Kollengodu-Subramanian, J. Zhao, and G.B. McKenna, Environmental Effects on the Structural Recovery Responses of an Epoxy Resin after Carbon Dioxide Pressure Jumps: Intrinsic Isopiestics, Asymmetry of Approach, and Memory Effect. Macromolecules, 2011. 44(10): p. 3828-3839.10.1021/ma1027577

99. Alcoutlabi, M., L. Banda, and G.B. McKenna, A comparison of concentration-glasses and temperature-hyperquenched glasses: CO2-formed glass versus temperature-formed glass. Polymer, 2004. 45(16): p. 5629-5634.10.1016/j.polymer.2004.04.004

100. Lee, M., M. Alcoutlabi, J.J. Magda, C. Dibble, M.J. Solomon, X. Shi, and G.B. McKenna, The effect of the shear-thickening transition of model colloidal spheres on the sign of N-1 and on the radial pressure profile in torsional shear flows. Journal of Rheology, 2006. 50(3): p. 293311.10.1122/1.2188567

101. Li, T., C. Wei, Y.-M. Wu, F.-D. Han, Y.-X. Qi, H.-L. Zhu, N. Lun, and Y.-J. Bai, Simple Preparation of Carbon Nanofibers with Graphene Layers Perpendicular to the Length Direction and the Excellent Li-lon Storage Performance. Acs Applied Materials \& Interfaces, 2015. 7(9): p. 51075115.10.1021/am508862e 
102. Li, W., M. Li, M. Wang, L. Zeng, and Y. Yu, Electrospinning with partially carbonization in air: Highly porous carbon nanofibers optimized for high-performance flexible lithium-ion batteries. Nano Energy, 2015. 13: p. 693-701.10.1016/j.nanoen.2015.03.027

103. Ramos, A., I. Camean, N. Cuesta, and A.B. Garcia, Graphitized stacked-cup carbon nanofibers as anode materials for lithium-ion batteries. Electrochimica Acta, 2014. 146: p. 769775.10.1016/j.electacta.2014.09.035

104. Zhu, J., L. Chen, Z. Xu, and B. Lu, Electrospinning preparation of ultra-long aligned nanofibers thin films for high performance fully flexible lithium-ion batteries. Nano Energy, 2015. 12: p. 339346.10.1016/j.nanoen.2014.10.026

105. He, D., F. Bai, L. Li, L. Shen, H.H. Kung, and N. Bao, Fabrication of Sandwich-structured Si Nanoparticles-Graphene Nanocomposites for High-performance Lithium-ion Batteries. Electrochimica Acta, 2015. 169: p. 409-415.10.1016/j.electacta.2015.04.090

106. Omampuliyur, R.S., M. Bhuiyan, Z. Han, Z. Jing, L. Li, E.A. Fitzgerald, C.V. Thompson, and W.K. Choi, Nanostructured Thin Film Silicon Anodes for Li-Ion Microbatteries. Journal of Nanoscience and Nanotechnology, 2015. 15(7): p. 4926-4933.10.1166/jnn.2015.9831

107. Yue, H., S. Wang, Z. Yang, Q. Li, S. Lin, and D. He, Ultra-thick porous films of grapheneencapsulated silicon nanoparticles as flexible anodes for lithium ion batteries. Electrochimica Acta, 2015. 174: p. 688-695.10.1016/j.electacta.2015.06.042

108. Zhu, H., F. Lyu, M. Du, M. Zhang, Q. Wane, J. Yao, and B. Guo, Design of Two-Dimensional, Ultrathin MoS2 Nanoplates Fabricated Within One-Dimensional Carbon Nanofibers With Thermosensitive Morphology: High-Performance Electrocatalysts For The Hydrogen Evolution Reaction. Acs Applied Materials \& Interfaces, 2014. 6(24): p. 22126-22137.10.1021/am505544g

109. Zhang, X.W., L.W. Ji, O. Toprakci, Y.Z. Liang, and M. Alcoutlabi, Electrospun Nanofiber-Based Anodes, Cathodes, and Separators for Advanced Lithium-Ion Batteries. Polymer Reviews, 2011. 51(3): p. 239-264.10.1080/15583724.2011.593390

110. Guo, J., B. Jiang, X. Zhang, and H. Liu, Monodisperse SnO2 anchored reduced graphene oxide nanocomposites as negative electrode with high rate capability and long cyclability for lithiumion batteries. Journal of Power Sources, 2014. 262(0): p. 1522.http://dx.doi.org/10.1016/j.jpowsour.2014.03.085

111. Lu, Y., K. Fu, S. Zhang, Y. Li, C. Chen, J. Zhu, M. Yanilmaz, M. Dirican, and X. Zhang, Centrifugal spinning: A novel approach to fabricate porous carbon fibers as binder-free electrodes for electric double-layer capacitors. Journal of Power Sources, 2015. 273: p. 502510.10.1016/j.jpowsour.2014.09.130

112. Meschini, I., F. Nobili, M. Mancini, R. Marassi, R. Tossici, A. Savoini, M.L. Focarete, and F. Croce, High-performance Sn@carbon nanocomposite anode for lithium batteries. Journal of Power Sources, 2013. 226(0): p. 241-248.http://dx.doi.org/10.1016/j.jpowsour.2012.11.004

113. Fleaca, C.T. and F. Le Normand, Ni-catalysed carbon nanotubes and nanofibers assemblies grown on TiN/Si(100) substrates using hot-filaments combined with d.c. plasma CVD. Physica ELow-Dimensional Systems \& Nanostructures, 2014. 56: p. 435-440.10.1016/j.physe.2012.11.026

114. Ghavanini, F.A., M.E.L. Damian, D. Rafieian, and P. Lundgren, Growth characterization of vertically aligned carbon nanofibers on top of TiN buffer layer for nanoelectromechanical devices, in Eurosensors Xxiv Conference, B. Jakoby and M.J. Vellekoop, Editors. 2010. p. 11151118.

115. Kim, W.S., Y. Hwa, J.H. Jeun, H.J. Sohn, and S.H. Hong, Synthesis of SnO2 nano hollow spheres and their size effects in lithium ion battery anode application. Journal of Power Sources, 2013. 225: p. 108-112.10.1016/j.jpowsour.2012.10.030 
116. Park, H., T. Song, H. Han, and U. Paik, Electrospun Li4Ti5O12 nanofibers sheathed with conductive TiN/TiOxNy layer as an anode material for high power Li-ion batteries. Journal of Power Sources, 2013. 244(0): p. 726-730.http://dx.doi.org/10.1016/j.jpowsour.2012.11.078

117. Tran, T., K. McCormac, J. Li, Z. Bi, and J. Wu, Electrospun SnO2 and TiO2 Composite Nanofibers for Lithium Ion Batteries. Electrochimica Acta, 2014. 117(0): p. 68-

75.http://dx.doi.org/10.1016/j.electacta.2013.11.101

118. Trinca, R.B., G.A. Abraham, and M.I. Felisberti, Electrospun nanofibrous scaffolds of segmented polyurethanes based on PEG, PLLA and PTMC blocks: Physico-chemical properties and morphology. Materials science \& engineering. C, Materials for biological applications, 2015. 56: p. 511-7.10.1016/j.msec.2015.07.018

119. Yang, H., T. Song, S. Lee, H. Han, F. Xia, A. Devadoss, W. Sigmund, and U. Paik, Tin indium oxide/graphene nanosheet nanocomposite as an anode material for lithium ion batteries with enhanced lithium storage capacity and rate capability. Electrochimica Acta, 2013. 91(0): p. 275281.http://dx.doi.org/10.1016/j.electacta.2012.12.070

120. El-Gendy, H., M. Alcoutlabi, M. Jemmett, M. Deo, J. Magda, R. Venkatesan, and A. Montesi, The Propagation of Pressure in a Gelled Waxy Oil Pipeline as Studied by Particle Imaging Velocimetry. Aiche Journal, 2012. 58(1): p. 302-311.10.1002/aic.12560

121. Yun, Q., X. Qin, W. Lv, Y.-B. He, B. Li, F. Kang, and Q.-H. Yang, "Concrete" inspired construction of a silicon/carbon hybrid electrode for high performance lithium ion battery. Carbon, 2015. 93: p. 59-67.10.1016/j.carbon.2015.05.032

122. Zeng, L., Y. Jiang, J. Xu, M. Wang, W. Li, and Y. Yu, Flexible copper-stabilized sulfur-carbon nanofibers with excellent electrochemical performance for Li-S batteries. Nanoscale, 2015. 7(25): p. 10940-10949.10.1039/c5nr01861g

123. Zhang, G., J. Zhu, W. Zeng, S. Hou, F. Gong, F. Li, C.C. Li, and H. Duan, Tin quantum dots embedded in nitrogen-doped carbon nanofibers as excellent anode for lithium-ion batteries. Nano Energy, 2014. 9: p. 61-70.10.1016/j.nanoen.2014.06.030

124. Zhou, H., X. Ding, G. Liu, Y. Jiang, Z. Yin, and X. Wang, Preparation and Characterization of Ultralong Spinel Lithium Manganese Oxide Nanofiber Cathode via Electrospinning Method. Electrochimica Acta, 2015. 152: p. 274-279.10.1016/j.electacta.2014.11.147

125. Zhuang, W., L. Li, J. Zhu, R. An, L. Lu, X. Lu, X. Wu, and H. Ying, Facile Synthesis of Mesoporous MoS2-TiO2 Nanofibers for Ultrastable Lithium Ion Battery Anodes. Chemelectrochem, 2015. 2(3): p. 374-381.10.1002/celc.201402358

126. Zou, M., J. Li, W. Wen, Y. Lin, H. Lai, and Z. Huang, Free-standing anode of N-doped carbon nanofibers containing $\mathrm{SnO}$ x for high-performance lithium batteries. Materials Research Bulletin, 2014. 60: p. 868-871.10.1016/j.materresbull.2014.09.086

127. Hoque, M.A., D.C. Higgins, F.M. Hassan, J.-Y. Choi, M.D. Pritzker, and Z. Chen, Tin oxide mesoporous carbon composites as platinum catalyst supports for ethanol oxidation and oxygen reduction. Electrochimica Acta, 2014. 121(0): p. 421-

427.http://dx.doi.org/10.1016/i.electacta.2013.12.075

128. Wang, J.W., Y. He, F. Fan, X.H. Liu, S. Xia, Y. Liu, C.T. Harris, H. Li, J.Y. Huang, S.X. Mao, and T. Zhu, Two-Phase Electrochemical Lithiation in Amorphous Silicon. Nano Letters, 2013. 13(2): p. 709-715.10.1021/nl304379k

129. Bridel, J.-S., S. Grugeon, S. Laruelle, J. Hassoun, P. Reale, B. Scrosati, and J.-M. Tarascon, Decomposition of ethylene carbonate on electrodeposited metal thin film anode. Journal of Power Sources, 2010. 195(7): p. 2036-2043.10.1016/j.jpowsour.2009.10.038

130. Inose, T., D. Watanabe, H. Morimoto, and S.-I. Tobishima, Influence of glyme-based nonaqueous electrolyte solutions on electrochemical properties of Si-based anodes for rechargeable lithium cells. Journal of Power Sources, 2006. 162(2): p. 1297-1303.10.1016/j.jpowsour.2006.08.005 
131. Mukhopadhyay, A. and B.W. Sheldon, Deformation and stress in electrode materials for Li-ion batteries. Progress in Materials Science, 2014. 63: p. 58-116.10.1016/j.pmatsci.2014.02.001

132. Bonino, C.A., L. Ji, Z. Lin, O. Toprakci, X. Zhang, and S.A. Khan, Electrospun Carbon-Tin Oxide Composite Nanofibers for Use as Lithium Ion Battery Anodes. Acs Applied Materials \& Interfaces, 2011. 3(7): p. 2534-2542.10.1021/am2004015

133. Jang, B.-O., S.-H. Park, and W.-J. Lee, Electrospun Co-Sn alloy/carbon nanofibers composite anode for lithium ion batteries. Journal of Alloys and Compounds, 2013. 574: p. 325330.http://dx.doi.org/10.1016/j.jallcom.2013.05.063

134. Kim, D., D. Lee, J. Kim, and J. Moon, Electrospun Ni-Added SnO2-Carbon Nanofiber Composite Anode for High-Performance Lithium-Ion Batteries. Acs Applied Materials \& Interfaces, 2012. 4(10): p. 5408-5415.10.1021/am301328u

135. Zhao, Y., X. Li, L. Dong, B. Yan, H. Shan, D. Li, and X. Sun, Electrospun SnO2-ZnO nanofibers with improved electrochemical performance as anode materials for lithium-ion batteries. International Journal of Hydrogen Energy, 2015. 40(41): p. 1433814344.http://dx.doi.org/10.1016/i.ijhydene.2015.06.054

136. Fu, Z.R., X.F. Li, and G.R. Xu, Novel electrospun SnO2@carbon nanofibers as high performance anodes for lithium-ion batteries. Crystal Research and Technology, 2014. 49(7): p. 441445.10.1002/crat.201300211

137. Ara, M., K. Wadumesthrige, T. Meng, S.O. Salley, and K.Y. Simon Ng, Effect of microstructure and $\mathrm{Sn} / \mathrm{C}$ ratio in SnO2-graphene nanocomposites for lithium-ion battery performance. Rsc Advances, 2014. 4(39): p. 20540-20547.10.1039/c4ra00851k

138. Shen, Z., Y. Hu, Y. Chen, X. Zhang, K. Wang, and R. Chen, Tin nanoparticle-loaded porous carbon nanofiber composite anodes for high current lithium-ion batteries. Journal of Power Sources, 2015. 278: p. 660-667.10.1016/j.jpowsour.2014.12.106

139. Wang, J., W.L. Song, Z.Y. Wang, L.Z. Fan, and Y.F. Zhang, Facile Fabrication of Binder-free Metallic Tin Nanoparticle/Carbon Nanofiber Hybrid Electrodes for Lithium-ion Batteries. Electrochimica Acta, 2015. 153: p. 468-475.10.1016/j.electacta.2014.12.026

140. Li, W., R. Yang, J. Zheng, and X.G. Li, Tandem plasma reactions for Sn/C composites with tunable structure and high reversible lithium storage capacity. Nano Energy, 2013. 2(6): p. 13141321.10.1016/j.nanoen.2013.06.012

141. Chen, C.-M. and P.-Y. Shih, A peculiar composite structure of carbon nanofibers growing on a microsized tin whisker. Journal of Materials Research, 2008. 23(10): p. 26682673.10.1557/jmr.2008.0326

142. Lee, B.-S., S.-B. Son, K.-M. Park, W.-R. Yu, K.-H. Oh, and S.-H. Lee, Anodic properties of hollow carbon nanofibers for Li-ion battery. Journal of Power Sources, 2012. 199(0): p. 5360.http://dx.doi.org/10.1016/j.jpowsour.2011.10.030

143. Tian, Q., Y. Tian, Z. Zhang, L. Yang, and S.-i. Hirano, Facile synthesis of ultrasmall tin oxide nanoparticles embedded in carbon as high-performance anode for lithium-ion batteries. Journal of Power Sources, 2014. 269(0): p. 479-485.http://dx.doi.org/10.1016/i.jpowsour.2014.07.019

144. Chen, J., L. Yang, S. Fang, Z. Zhang, A. Deb, and S.-i. Hirano, Sn-contained N-rich carbon nanowires for high-capacity and long-life lithium storage. Electrochimica Acta, 2014. 127(0): p. 390-396.http://dx.doi.org/10.1016/i.electacta.2014.02.066

145. Duan, B., W. Wang, K. Yuan, A. Wang, H. Zhao, and Y. Yang, Preparation and Electrochemical Properties of Sn/C Composite Anode Materials. Rare Metal Materials and Engineering, 2012. 41: p. 496-499

146. Kim, I.S., P.N. Kumta, and G.E. Blomgren, Chemically derived nano-encapsulated tin-carbon composite anodes for Li-ion batteries, in Developments in Solid Oxide Fuel Cells and Lithium Ion Batteries, A. Manithiram, et al., Editors. 2005. p. 131-140. 
147. Reale, P., M. Morcrette, and J. Hassoun, In-Situ X-Ray Diffraction Study of the Li-Alloying Electrochemical Process in a Tin-Carbon Nanocomposite Electrode. Nanoscience and Nanotechnology Letters, 2012. 4(2): p. 132-135.10.1166/nnl.2012.1295

148. Zhu, J., G.H. Zhang, S.Z. Gu, and B.G. Lu, SnO2 Nanorods on ZnO Nanofibers: A New Class of Hierarchical Nanostructures Enabled by Electrospinning as Anode Material for High-Performance Lithium-Ion Batteries. Electrochimica Acta, 2014. 150: p. 308-

313.10.1016/j.electacta.2014.10.149

149. Jang, B.O., S.H. Park, and W.J. Lee, Electrospun Co-Sn alloy/carbon nanofibers composite anode for lithium ion batteries. Journal of Alloys and Compounds, 2013. 574: p. 325330.10.1016/j.jallcom.2013.05.063

150. Xie, W., S. Li, S. Wang, S. Xue, Z. Liu, X. Jiang, and D. He, N-Doped Amorphous Carbon Coated Fe304/SnO2 Coaxial Nanofibers as a Binder-Free Self-Supported Electrode for Lithium Ion Batteries. Acs Applied Materials \& Interfaces, 2014. 6(22): p. 20334-20339.10.1021/am505829v

151. Lei, D., B. Qu, H.-T. Lin, and T. Wang, Facile approach to prepare porous GeO2/SnO2 nanofibers via a single spinneret electrospinning technique as anodes for Lithium-ion batteries. Ceramics International, 2015. 41(8): p. 10308-10313.http://dx.doi.org/10.1016/j.ceramint.2015.04.085

152. Chan, C.K., H. Peng, G. Liu, K. Mcllwrath, X.F. Zhang, R.A. Huggins, and Y. Cui, High-performance lithium battery anodes using silicon nanowires. Nat Nano, 2008. 3(1): p. 3135.http://www.nature.com/nnano/journal/v3/n1/suppinfo/nnano.2007.411 S1.html

153. Li, W., M. Li, Z. Yang, J. Xu, X. Zhong, J. Wang, L. Zeng, X. Liu, Y. Jiang, X. Wei, L. Gu, and Y. Yu, Carbon-Coated Germanium Nanowires on Carbon Nanofibers as Self-Supported Electrodes for Flexible Lithium-Ion Batteries. Small, 2015. 11(23): p. 2762-2767.10.1002/smll.201403533

154. Liu, S.K., W. He, X.D. Zhang, H.M. Li, S.Z. Zhang, and Y. Wang, Novel Nanostructure Designs for High-Performance Silicon Based Anodes. Energy and Environment Focus, 2015. 4(3): p. 178190.10.1166/eef.2015.1169

155. Ge, M., S. Kim, A. Nie, R. Shahbazian-Yassar, M. Mecklenburg, Y. Lu, X. Fang, C. Shen, J. Rong, S.Y. Park, D.S. Kim, J.Y. Kim, and C. Zhou, Capacity retention behavior and morphology evolution of SixGe1-x nanoparticles as lithium-ion battery anode. Nanotechnology, 2015. 26(25).25570210.1088/0957-4484/26/25/255702

156. Jamnongkan, T., S.K. Sukumaran, M. Sugimoto, T. Hara, Y. Takatsuka, and K. Koyama, Towards novel wound dressings: antibacterial properties of zinc oxide nanoparticles and electrospun fiber mats of zinc oxide nanoparticle/poly(vinyl alcohol) hybrids. Journal of Polymer Engineering, 2015. 35(6): p. 575-586.10.1515/polyeng-2014-0319

157. Zhou, M., X. Li, B. Wang, Y. Zhang, J. Ning, Z. Xiao, X. Zhang, Y. Chang, and L. Zhi, HighPerformance Silicon Battery Anodes Enabled by Engineering Graphene Assemblies. Nano letters, 2015. 15(9): p. 6222-8.10.1021/acs.nanolett.5b02697

158. Polat, B.D. and O. Keles, The effect of copper coating on nanocolumnar silicon anodes for lithium ion batteries. Thin Solid Films, 2015. 589: p. 543-550.http://dx.doi.org/10.1016/j.tsf.2015.06.038

159. Xu, K.Q., L.B. Ben, H. Li, and X.J. Huang, Silicon-based nanosheets synthesized by a topochemical reaction for use as anodes for lithium ion batteries. Nano Research, 2015. 8(8): p. 26542662.10.1007/s12274-015-0772-4

160. Wang, W., Y. Wang, L. Gu, R. Lu, H. Qian, X. Peng, and J. Sha, SiC@Si core-shell nanowires on carbon paper as a hybrid anode for lithium-ion batteries. Journal of Power Sources, 2015. 293: p. 492-497.10.1016/j.jpowsour.2015.05.103

161. Zhou, H., X. Wang, and D. Chen, Li-Metal-Free Prelithiation of Si-Based Negative Electrodes for Full Li-Ion Batteries. ChemSusChem, 2015. 8(16): p. 2737-2744.10.1002/cssc.201500287 
162. Wang, M.S., W.L. Song, J. Wang, and L.Z. Fan, Highly uniform silicon nanoparticle/porous carbon nanofiber hybrids towards free-standing high-performance anodes for lithium-ion batteries. Carbon, 2015. 82: p. 337-345.10.1016/j.carbon.2014.10.078

163. Nguyen Trung, H., J. Suk, D.W. Kim, O.H. Chung, J.S. Park, and Y. Kang, Silicon nanoparticle and carbon nanotube loaded carbon nanofibers for use in lithium-ion battery anodes. Synthetic Metals, 2014. 198: p. 36-40.10.1016/j.synthmet.2014.09.021

164. Park, E., H. Yoo, J. Lee, M.-S. Park, Y.-J. Kim, and H. Kim, Dual-Size Silicon Nanocrystal-Embedded SiOx Nanocomposite as a High-Capacity Lithium Storage Material. Acs Nano, 2015. 9(7): p. 76907696.10.1021/acsnano.5b03166

165. Wang, X., M. Xi, F. Zheng, B. Ding, H. Fong, and Z. Zhu, Reduction of crack formation in TiO2 mesoporous films prepared from binder-free nanoparticle pastes via incorporation of electrospun SiO2 or TiO2 nanofibers for dye-sensitized solar cells. Nano Energy, 2015. 12: p. 794800.10.1016/j.nanoen.2015.01.045

166. Choi, Y.S., M. Pharr, K.H. Oh, and J.J. Vlassak, A simple technique for measuring the fracture energy of lithiated thin-film silicon electrodes at various lithium concentrations. Journal of Power Sources, 2015. 294: p. 159-166.10.1016/j.jpowsour2015.06.063

167. Li, J. and J. Huang, A nanofibrous polypyrrole/silicon composite derived from cellulose substance as the anode material for lithium-ion batteries. Chemical communications (Cambridge, England), 2015. 51(78): p. 14590-3.10.1039/c5cc05300e

168. Pandey, G.P., S.A. Klankowski, Y. Li, X.S. Sun, J. Wu, R.A. Rojeski, and J. Li, Effective Infiltration of Gel Polymer Electrolyte into Silicon-Coated Vertically Aligned Carbon Nanofibers as Anodes for Solid-State Lithium-Ion Batteries. Acs Applied Materials \& Interfaces, 2015. 7(37): p. 2090918.10.1021/acsami.5b06444

169. Schmuelling, G., M. Winter, and T. Placke, Investigating the Mg-Si Binary System via Combinatorial Sputter Deposition As High Energy Density Anodes for Lithium-Ion Batteries. Acs Applied Materials \& Interfaces, 2015. 7(36): p. 20124-33.10.1021/acsami.5b05382

170. Yamano, A., M. Morishita, H. Yamauchi, T. Nagakane, M. Ohji, A. Sakamoto, M. Yanagida, and T. Sakai, Electrochemical and safety performance of Li pre-doping free cell using tin-phosphate glass-silicon composite anode. Journal of Power Sources, 2015. 292: p. 3138.10.1016/j.jpowsour.2015.05.026

171. Chou, C.-Y., J.-H. Seo, Y.-H. Tsai, J.-P. Ahn, E. Paek, M.-H. Cho, I.-S. Choi, and G.S. Hwang, Anomalous Stagewise Lithiation of Gold-Coated Silicon Nanowires: A Combined In Situ Characterization and First-Principles Study. Acs Applied Materials \& Interfaces, 2015. 7(31): p. 16976-16983.10.1021/acsami.5b01930

172. Liu, J., P. Kopold, P.A. van Aken, J. Maier, and Y. Yu, Energy Storage Materials from Nature through Nanotechnology: A Sustainable Route from Reed Plants to a Silicon Anode for LithiumIon Batteries. Angewandte Chemie-International Edition, 2015. 54(33): p. 96329636.10.1002/anie.201503150

173. Dirican, M., Y. Lu, K. Fu, H. Kizil, and X. Zhang, SiO2-confined silicon/carbon nanofiber composites as an anode for lithium-ion batteries. Rsc Advances, 2015. 5(44): p. 3474434751.10.1039/c5ra03129j

174. Lee, B.-S., H.-S. Yang, H. Jung, S.-Y. Jeon, C. Jung, S.-W. Kim, J. Bae, C.-L. Choong, J. Im, U.I. Chung, J.-J. Park, and W.-R. Yu, Novel multi-layered 1-D nanostructure exhibiting the theoretical capacity of silicon for a super-enhanced lithium-ion battery. Nanoscale, 2014. 6(11): p. 59895998.10.1039/c4nr00318g

175. Li, Q., L. Yin, J. Ma, Z. Li, Z. Zhang, A. Chen, and C. Li, Mesoporous silicon/carbon hybrids with ordered pore channel retention and tunable carbon incorporated content as high performance 
anode materials for lithium-ion batteries. Energy, 2015. 85: p. 159166.10.1016/j.energy.2015.03.090

176. Wang, M., D. Jia, J. Li, and J. Huang, Nanofibrous silicon/carbon composite sheet derived from cellulose substance as free-standing lithium-ion battery anodes. Rsc Advances, 2014. 4(64): p. 33981-33985.10.1039/c4ra05820h

177. Wang, Y., J. Chen, and S. Wang, Mesoporous silicon/carbon nanofibers composites anode materials for Li-ion battery. Abstracts of Papers of the American Chemical Society, 2014. 247

178. Wu, Q., T. Tran, W. Lu, and J. Wu, Electrospun silicon/carbon/titanium oxide composite nanofibers for lithium ion batteries. Journal of Power Sources, 2014. 258: p. 3945.10.1016/j.jpowsour.2014.02.047

179. Zhang, C., R. Yu, T. Zhou, Z. Chen, H. Liu, and Z. Guo, Mass production of three-dimensional hierarchical microfibers constructed from silicon-carbon core-shell architectures with highperformance lithium storage. Carbon, 2014. 72: p. 169-175.10.1016/j.carbon.2014.01.069

180. Zhang, H., X. Qin, J. Wu, Y.-B. He, H. Du, B. Li, and F. Kang, Electrospun core-shell silicon/carbon fibers with an internal honeycomb-like conductive carbon framework as an anode for lithium ion batteries. Journal of Materials Chemistry A, 2015. 3(13): p. 7112-7120.10.1039/c4ta06044j

181. Zhang, M., X. Hou, J. Wang, M. Li, S. Hu, Z. Shao, and X. Liu, Interweaved Si@C/CNTs\&CNFs composites as anode materials for Li-ion batteries. Journal of Alloys and Compounds, 2014. 588 : p. 206-211.10.1016/j.jallcom.2013.10.160

182. Chen, P.-C., J. Xu, H. Chen, and C. Zhou, Hybrid silicon-carbon nanostructured composites as superior anodes for lithium ion batteries. Nano Research, 2011. 4(3): p. 290296.10.1007/s12274-010-0081-x

183. Choi, J.W., L. Hu, L. Cui, J.R. McDonough, and Y. Cui, Metal current collector-free freestanding silicon-carbon 1D nanocomposites for ultralight anodes in lithium ion batteries. Journal of Power Sources, 2010. 195(24): p. 8311-8316.10.1016/j.jpowsour.2010.06.108

184. Guo, J., A. Sun, X. Chen, C. Wang, and A. Manivannan, Cyclability study of silicon-carbon composite anodes for lithium-ion batteries using electrochemical impedance spectroscopy. Electrochimica Acta, 2011. 56(11): p. 3981-3987.10.1016/j.electacta.2011.02.014

185. Wang, J.W., X.H. Liu, K. Zhao, A. Palmer, E. Patten, D. Burton, S.X. Mao, Z. Suo, and J.Y. Huang, Sandwich-Lithiation and Longitudinal Crack in Amorphous Silicon Coated on Carbon Nanofibers. Acs Nano, 2012. 6(10): p. 9158-9167.10.1021/nn3034343

186. Wang, W. and P.N. Kumta, Nanostructured Hybrid Silicon/Carbon Nanotube Heterostructures: Reversible High-Capacity Lithium-Ion Anodes. Acs Nano, 2010. 4(4): p. 22332241.10.1021/nn901632g

187. Ji, L.W., O. Toprakci, M. Alcoutlabi, Y.F. Yao, Y. Li, S. Zhang, B.K. Guo, Z. Lin, and X.W. Zhang, alpha-Fe2O3 Nanoparticle-Loaded Carbon Nanofibers as Stable and High-Capacity Anodes for Rechargeable Lithium-Ion Batteries. Acs Applied Materials \& Interfaces, 2012. 4(5): p. 26722679.10.1021/am300333s

188. Kim, J.H., Y.J. Hong, Y.C. Kang, Y.J. Choi, and Y.S. Kim, Superior electrochemical properties of alpha-Fe2O3 nanofibers with a porous core/dense shell structure formed from iron acetylacetonate-polyvinylpyrrolidone composite fibers. Electrochimica Acta, 2015. 154: p. 211218.10.1016/j.electacta.2014.11.181

189. Li, J., W. Wen, G. Xu, M. Zou, Z. Huang, and L. Guan, Fe-added Fe3C carbon nanofibers as anode for Li ion batteries with excellent low-temperature performance. Electrochimica Acta, 2015. 153: p. 300-305.10.1016/j.electacta.2014.12.008

190. Luo, L., R. Cui, H. Qiao, K. Chen, Y. Fei, D. Li, Z. Pang, K. Liu, and Q. Wei, High lithium electroactivity of electrospun CuFe2O4 nanofibers as anode material for lithium-ion batteries. Electrochimica Acta, 2014. 144: p. 85-91.10.1016/j.electacta.2014.08.048 
191. Wan, Y., Z. Yang, G. Xiong, R. Guo, Z. Liu, and H. Luo, Anchoring Fe3O4 nanoparticles on threedimensional carbon nanofibers toward flexible high-performance anodes for lithium-ion batteries. Journal of Power Sources, 2015. 294: p. 414-419.10.1016/j.jpowsour.2015.06.057

192. Zou, M., J. Li, W. Wen, L. Chen, L. Guan, H. Lai, and Z. Huang, Silver-incorporated composites of $\mathrm{Fe} 2 \mathrm{O} 3$ carbon nanofibers as anodes for high-performance lithium batteries. Journal of Power Sources, 2014. 270: p. 468-474.10.1016/j.jpowsour.2014.07.119

193. Ji, L., O. Toprakci, M. Alcoutlabi, Y. Yao, Y. Li, S. Zhang, B. Guo, Z. Lin, and X. Zhang, alpha-Fe2O3 Nanoparticle-Loaded Carbon Nanofibers as Stable and High-Capacity Anodes for Rechargeable Lithium-Ion Batteries. Acs Applied Materials \& Interfaces, 2012. 4(5): p. 26722679.10.1021/am300333s

194. Wu, C., X. Li, W. Li, B. Li, Y. Wang, Y. Wang, M. Xu, and L. Xing, Fe2O3 nanorods/carbon nanofibers composite: Preparation and performance as anode of high rate lithium ion battery. Journal of Power Sources, 2014. 251: p. 85-91.10.1016/j.jpowsour.2013.11.030

195. Zhang, X., H. Liu, S. Petnikota, S. Ramakrishna, and H.J. Fan, Electrospun Fe2O3-carbon composite nanofibers as durable anode materials for lithium ion batteries. Journal of Materials Chemistry A, 2014. 2(28): p. 10835-10841.10.1039/c3ta15123a

196. Büyükyazi, M. and S. Mathur, 3D nanoarchitectures of $\alpha$-LiFeO2 and $\alpha$-LiFeO2/C nanofibers for high power lithium-ion batteries. Nano Energy, 2015. 13: p. 2835.http://dx.doi.org/10.1016/j.nanoen.2015.02.005

197. Qiao, H., L. Luo, K. Chen, Y. Fei, R. Cui, and Q. Wei, Electrospun synthesis and lithium storage properties of magnesium ferrite nanofibers. Electrochimica Acta, 2015. 160: p. 4349.10.1016/j.electacta.2015.02.012

198. Qin, X.Y., H.R. Zhang, J.X. Wu, X.D. Chu, Y.B. He, C.P. Han, C. Miao, S.A. Wang, B.H. Li, and F.Y. Kang, Fe3O4 nanoparticles encapsulated in electrospun porous carbon fibers with a compact shell as high-performance anode for lithium ion batteries. Carbon, 2015. 87: p. 347356.10.1016/j.carbon.2015.02.044

199. Kalluri, S., W.K. Pang, K.H. Seng, Z. Chen, Z. Guo, H.K. Liu, and S.X. Dou, One-dimensional nanostructured design of $\mathrm{Li1}+\mathrm{x}(\mathrm{Mn1} / 3 \mathrm{Ni1} / 3 \mathrm{Fe} 1 / 3) \mathrm{O} 2$ as a dual cathode for lithium-ion and sodium-ion batteries. Journal of Materials Chemistry A, 2015. 3(1): p. 250257.10.1039/c4ta04271a

200. Kim, C., B.R. Kim, and J.T. Son, Synthesis mechanism of new morphology LiMnPO4 nanofibers using electrospinning process. Journal of Electroceramics, 2014. 33(1-2): p. 711.10.1007/s10832-014-9893-5

201. Xu, G., J. Li, X. Li, H. Zhou, X. Ding, X. Wang, and F. Kang, Understanding the electrochemical

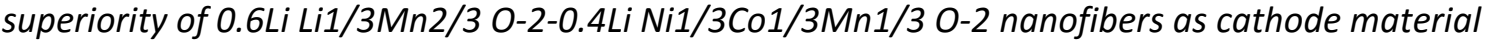
for lithium ion batteries. Electrochimica Acta, 2015. 173: p. 672679.10.1016/j.electacta.2015.05.083

202. Yan, B., X. Li, Z. Bai, M. Li, L. Dong, D. Xiong, and D. Li, Superior lithium storage performance of hierarchical porous vanadium pentoxide nanofibers for lithium ion battery cathodes. Journal of Alloys and Compounds, 2015. 634: p. 50-57.10.1016/j.jallcom.2015.01.292

203. Mai, L., L. Xu, C. Han, X. Xu, Y. Luo, S. Zhao, and Y. Zhao, Electrospun Ultralong Hierarchical Vanadium Oxide Nanowires with High Performance for Lithium Ion Batteries. Nano letters, 2010. 10(11): p. 4750-4755.10.1021/nl103343w

204. Li, Z., G. Liu, M. Guo, L.-X. Ding, S. Wang, and H. Wang, Electrospun porous vanadium pentoxide nanotubes as a high-performance cathode material for lithium-ion batteries. Electrochimica Acta, 2015. 173: p. 131-138.http://dx.doi.org/10.1016/j.electacta.2015.05.057

205. Whittingham, M.S., Lithium Batteries and Cathode Materials. Chemical Reviews, 2004. 104(10): p. 4271-4302.10.1021/cr020731c 
206. Du Pasquier, A., C.C. Huang, and T. Spitler, Nano Li4Ti5012-LiMn2O4 batteries with high power capability and improved cycle-life. Journal of Power Sources, 2009. 186(2): p. 508-

514.http://dx.doi.org/10.1016/j.jpowsour.2008.10.018

207. Belharouak, I., Y.-K. Sun, W. Lu, and K. Amine, On the Safety of the Li4Ti5O12/LiMn2O4 LithiumIon Battery System. Journal of the Electrochemical Society, 2007. 154(12): p. A1083A1087.10.1149/1.2783770

208. Cheng, X.B., Q. Zhang, H.F. Wang, G.L. Tian, J.Q. Huang, H.J. Peng, M.Q. Zhao, and F. Wei, Nitrogen-doped herringbone carbon nanofibers with large lattice spacings and abundant edges: Catalytic growth and their applications in lithium ion batteries and oxygen reduction reactions. Catalysis Today, 2015. 249: p. 244-251.10.1016/j.cattod.2014.10.047

209. Liu, Q., D. Mao, C. Chang, and F. Huang, Phase conversion and morphology evolution during hydrothermal preparation of orthorhombic LiMnO2 nanorods for lithium ion battery application. Journal of Power Sources, 2007. 173(1): p. 538-544.10.1016/j.jpowsour.2007.03.077

210. Molenda, J., M. Ziemnicki, J. Marzec, W. Zajac, M. Molenda, and M. Bucko, Electrochemical and high temperature physicochemical properties of orthorhombic LiMnO2. Journal of Power Sources, 2007. 173(2): p. 707-711.10.1016/j.jpowsour.2007.05.054

211. Thackeray, M.M., L.A. de Picciotto, A. de Kock, P.J. Johnson, V.A. Nicholas, and K.T. Adendorff, Spinel electrodes for lithium batteries - A review. Journal of Power Sources, 1987. 21(1): p. 18.http://dx.doi.org/10.1016/0378-7753(87)80071-X

212. Matsushima, T., Deterioration estimation of lithium-ion cells in direct current power supply systems and characteristics of 400-Ah lithium-ion cells. Journal of Power Sources, 2009. 189(1): p. 847-854.10.1016/j.jpowsour.2008.08.023

213. Deng, B.H., H. Nakamura, and M. Yoshio, Capacity fading with oxygen loss for manganese spinels upon cycling at elevated temperatures. Journal of Power Sources, 2008. 180(2): p. 864868.10.1016/j.jpowsour.2008.02.071

214. Xu, H., X. Hu, Y. Sun, W. Luo, C. Chen, Y. Liu, and Y. Huang, Highly porous Li4Ti5012/C nanofibers for ultrafast electrochemical energy storage. Nano Energy, 2014. 10: p. 163171.10.1016/j.nanoen.2014.09.003

215. Lin, H.-Y., S.-M. Yeh, and J.-S. Chen, Physical and Electrochemical Properties of LiFePO4/C Nanofibers Synthesized by Electrospinning. International Journal of Electrochemical Science, 2014. 9(12): p. 6936-6948

216. Manthiram, A., S.H. Chung, and C.X. Zu, Lithium-Sulfur Batteries: Progress and Prospects. Advanced Materials, 2015. 27(12): p. 1980-2006.10.1002/adma.201405115

217. Manthiram, A., Y.Z. Fu, S.H. Chung, C.X. Zu, and Y.S. Su, Rechargeable Lithium-Sulfur Batteries. Chemical Reviews, 2014. 114(23): p. 11751-11787.10.1021/cr500062v

218. Scheers, J., S. Fantini, and P. Johansson, A review of electrolytes for lithium-sulphur batteries. Journal of Power Sources, 2014. 255: p. 204-218.10.1016/j.jpowsour.2014.01.023

219. Bresser, D., S. Passerini, and B. Scrosati, Recent progress and remaining challenges in sulfurbased lithium secondary batteries - a review. Chemical Communications, 2013. 49(90): p. 1054510562.10.1039/c3cc46131a

220. Lin, Z. and C.D. Liang, Lithium-sulfur batteries: from liquid to solid cells. Journal of Materials Chemistry A, 2015. 3(3): p. 936-958.10.1039/c4ta04727c

221. Mikhaylik, Y.V. and J.R. Akridge, Low temperature performance of Li/S batteries. Journal of the Electrochemical Society, 2003. 150(3): p. A306-A311.10.1149/1.1545452

222. Agostini, M. and J. Hassoun, A lithium-ion sulfur battery using a polymer, polysulfide-added membrane. Scientific Reports, 2015. 5.Artn 759110.1038/Srep07591 
223. Li, Q., Z. Zhang, K. Zhang, J. Fang, Y. Lai, and J. Li, A simple synthesis of hollow carbon nanofibersulfur composite via mixed-solvent process for lithium-sulfur batteries. Journal of Power Sources, 2014. 256: p. 137-144.http://dx.doi.org/10.1016/j.jpowsour.2014.01.063

224. Chen, Y.M., X.Y. Li, K.S. Park, J.H. Hong, J. Song, L.M. Zhou, Y.W. Mai, H.T. Huang, and J.B. Goodenough, Sulfur encapsulated in porous hollow CNTs@CNFs for high-performance lithium sulfur batteries. Journal of Materials Chemistry A, 2014. 2(26): p. 1012610130.10.1039/c4ta01823k

225. Huang, L., J.L. Cheng, G.X. Qu, X.D. Li, Y. Hu, W. Ni, D.M. Yuan, Y. Zhang, and B. Wang, Porous carbon nanofibers formed in situ by electrospinning with a volatile solvent additive into an ice water bath for lithium-sulfur batteries. Rsc Advances, 2015. 5(30): p. 2374923757.10.1039/c4ra14680h

226. Ji, L.W., M.M. Rao, S. Aloni, L. Wang, E.J. Cairns, and Y.G. Zhang, Porous carbon nanofiber-sulfur composite electrodes for lithium/sulfur cells. Energy \& Environmental Science, 2011. 4(12): p. 5053-5059.10.1039/c1ee02256c

227. Kim, D.S. and Y.J. Park, Buckypaper electrode containing carbon nanofiber/Co3O4 composite for enhanced lithium air batteries. Solid State Ionics, 2014. 268, Part B: p. 216221.http://dx.doi.org/10.1016/j.ssi.2014.03.010

228. Li, X. and X.A. Sun, Nitrogen-doped carbons in Li-S batteries: materials design and electrochemical mechanism. Frontiers in Energy Research, 2014. 2.10.3389/fenrg.2014.00049

229. Li, Z., J.T. Zhang, and X.W. Lou, Hollow Carbon Nanofibers Filled with MnO2 Nanosheets as Efficient Sulfur Hosts for Lithium-Sulfur Batteries. Angewandte Chemie-International Edition, 2015. 54(44): p. 12886-12890.10.1002/anie.201506972

230. Lu, S.T., Y. Chen, X.H. Wu, Z.D. Wang, L.Y. Lv, W. Qin, and L.X. Jiang, Binder-free cathodes based on sulfur-carbon nanofibers composites for lithium-sulfur batteries. Rsc Advances, 2014. 4(35): p. 18052-18064.10.1039/c4ra02122c

231. Lu, S.T., Y.W. Cheng, X.H. Wu, and J. Liu, Significantly Improved Long-Cycle Stability in High-Rate Li-S Batteries Enabled by Coaxial Graphene Wrapping over Sulfur-Coated Carbon Nanofibers. Nano Letters, 2013. 13(6): p. 2485-2489.10.1021/nl400543y

232. Rao, M.M., W.S. Li, and E.J. Cairns, Porous carbon-sulfur composite cathode for lithium/sulfur cells. Electrochemistry Communications, 2012. 17: p. 1-5.10.1016/j.elecom.2011.12.022

233. Rao, M.M., X.Y. Song, and E.J. Cairns, Nano-carbon/sulfur composite cathode materials with carbon nanofiber as electrical conductor for advanced secondary lithium/sulfur cells. Journal of Power Sources, 2012. 205: p. 474-478.10.1016/j.jpowsour.2012.01.047

234. Tang, H., S.S. Yao, M.X. Jing, X. Wu, J.L. Hou, X.Y. Qian, D.W. Rao, X.Q. Shen, X.M. Xi, and K.S. Xiao, Mg0.6NiO.4O hollow nanofibers prepared by electrospinning as additive for improving electrochemical performance of lithium-sulfur batteries. Journal of Alloys and Compounds, 2015. 650: p. 351-356.10.1016/j.jallcom.2015.07.264

235. Ye, J., F. He, J. Nie, Y.L. Cao, H.X. Yang, and X.P. Ai, Sulfur/carbon nanocomposite-filled polyacrylonitrile nanofibers as a long life and high capacity cathode for lithium-sulfur batteries. Journal of Materials Chemistry A, 2015. 3(14): p. 7406-7412.10.1039/c4ta06976e

236. Zeng, L.C., Y. Jiang, J. Xu, M. Wang, W.H. Li, and Y. Yu, Flexible copper-stabilized sulfur-carbon nanofibers with excellent electrochemical performance for Li-S batteries. Nanoscale, 2015. 7(25): p. 10940-10949.10.1039/c5nr01861g

237. Zeng, L.C., F.S. Pan, W.H. Li, Y. Jiang, X.W. Zhong, and Y. Yu, Free-standing porous carbon nanofibers-sulfur composite for flexible Li-S battery cathode. Nanoscale, 2014. 6(16): p. 95799587.10.1039/c4nr02498b 
238. Zhang, W.H., D. Qiao, J.X. Pan, Y.L. Cao, H.X. Yang, and X.P. Ai, A Li+-conductive microporous carbon-sulfur composite for Li-S batteries. Electrochimica Acta, 2013. 87: p. 497502.10.1016/j.electacta.2012.09.086

239. Zhang, Z., Q. Li, S.F. Jiang, K. Zhang, Y.Q. Lai, and J. Li, Sulfur Encapsulated in a TiO2-Anchored Hollow Carbon Nanofiber Hybrid Nanostructure for Lithium-Sulfur Batteries. Chemistry-a European Journal, 2015. 21(3): p. 1343-1349.10.1002/chem.201404686

240. Zhou, F., S. Xin, H.-W. Liang, L.-T. Song, and S.-H. Yu, Carbon Nanofibers Decorated with Molybdenum Disulfide Nanosheets: Synergistic Lithium Storage and Enhanced Electrochemical Performance. Angewandte Chemie-International Edition, 2014. 53(43): p. 1155211556.10.1002/anie.201407103

241. Fu, K., Y.P. Li, M. Dirican, C. Chen, Y. Lu, J.D. Zhu, Y. Li, L.Y. Cao, P.D. Bradford, and X.W. Zhang, Sulfur gradient-distributed CNF composite: a self-inhibiting cathode for binder-free lithium-sulfur batteries. Chemical Communications, 2014. 50(71): p. 10277-10280.10.1039/c4cc04970e

242. Wu, Y.H., M.X. Gao, X. Li, Y.F. Liu, and H.G. Pan, Preparation of mesohollow and microporous carbon nanofiber and its application in cathode material for lithium-sulfur batteries. Journal of Alloys and Compounds, 2014. 608: p. 220-228.10.1016/j.jallcom.2014.04.073

243. Zheng, G.Y., Y. Yang, J.J. Cha, S.S. Hong, and Y. Cui, Hollow Carbon Nanofiber-Encapsulated Sulfur Cathodes for High Specific Capacity Rechargeable Lithium Batteries. Nano Letters, 2011. 11(10): p. 4462-4467.10.1021/nl2027684

244. Zheng, G.Y., Q.F. Zhang, J.J. Cha, Y. Yang, W.Y. Li, Z.W. Seh, and Y. Cui, Amphiphilic Surface Modification of Hollow Carbon Nanofibers for Improved Cycle Life of Lithium Sulfur Batteries. Nano Letters, 2013. 13(3): p. 1265-1270.10.1021/nl304795g

245. Yao, H.B., G.Y. Zheng, W.Y. Li, M.T. McDowell, Z.W. Seh, N.A. Liu, Z.D. Lu, and Y. Cui, Crab Shells as Sustainable Templates from Nature for Nanostructured Battery Electrodes. Nano Letters, 2013. 13(7): p. 3385-3390.10.1021/nl401729r

246. He, G., B. Mandlmeier, J. Schuster, L.F. Nazar, and T. Bein, Bimodal Mesoporous Carbon Nanofibers with High Porosity: Freestanding and Embedded in Membranes for Lithium-Sulfur Batteries. Chemistry of Materials, 2014. 26(13): p. 3879-3886.10.1021/cm403740r

247. Yang, J., J. Xie, X.Y. Zhou, Y.L. Zou, J.J. Tang, S.C. Wang, F. Chen, and L.Y. Wang, Functionalized NDoped Porous Carbon Nanofiber Webs for a Lithium-Sulfur Battery with High Capacity and Rate Performance. Journal of Physical Chemistry C, 2014. 118(4): p. 1800-1807.10.1021/jp410385s

248. Zhou, L., X.J. Lin, T. Huang, and A.S. Yu, Nitrogen-doped porous carbon nanofiber webs/sulfur composites as cathode materials for lithium-sulfur batteries. Electrochimica Acta, 2014. 116: p. 210-216.10.1016/j.electacta.2013.11.041

249. Elazari, R., G. Salitra, A. Garsuch, A. Panchenko, and D. Aurbach, Sulfur-Impregnated Activated Carbon Fiber Cloth as a Binder-Free Cathode for Rechargeable Li-S Batteries. Advanced Materials, 2011. 23(47): p. 5641-+.10.1002/adma.201103274

250. Wang, C., J.H. Jheng, and F.C. Chiu, Electrospun nylon-4, 6 nanofibers: solution rheology and Brill transition. Colloid and Polymer Science, 2013. 291(10): p. 2337-2344.10.1007/s00396-013-29705

251. Choi, Y.J., K.W. Kim, H.J. Ahn, and J.H. Ahn, Improvement of cycle property of sulfur electrode for lithium/sulfur battery. Journal of Alloys and Compounds, 2008. 449(1-2): p. 313316.10.1016/j.jallcom.2006.02.098

252. Singhal, R., S.H. Chung, A. Manthiram, and V. Kalra, A free-standing carbon nanofiber interlayer for high-performance lithium-sulfur batteries. Journal of Materials Chemistry A, 2015. 3(8): p. 4530-4538.10.1039/c4ta06511e 
253. Wang, J.G., Y. Yang, and F.Y. Kang, Porous carbon nanofiber paper as an effective interlayer for high-performance lithium-sulfur batteries. Electrochimica Acta, 2015. 168: p. 271276.10.1016/j.electacta.2015.04.055

254. Zhao, B., N.W. Li, H.L. Lu, Z.X. Lin, and M.B. Zheng, Mesoporous Carbon Nanofiber-Sulfur Cathode for Lithium-Sulfur Batteries. Chinese Journal of Inorganic Chemistry, 2014. 30(4): p. 733740

255. Chen, L. and L.L. Shaw, Recent advances in lithium-sulfur batteries. Journal of Power Sources, 2014. 267: p. 770-783.10.1016/j.jpowsour.2014.05.111

256. Vizintin, A., M.U.M. Patel, B. Genorio, and R. Dominko, Effective Separation of Lithium Anode and Sulfur Cathode in Lithium-Sulfur Batteries. Chemelectrochem, 2014. 1(6): p. 10401045.10.1002/celc.201402039

257. Yin, Y.X., S. Xin, Y.G. Guo, and L.J. Wan, Lithium-Sulfur Batteries: Electrochemistry, Materials, and Prospects. Angewandte Chemie-International Edition, 2013. 52(50): p. 1318613200.10.1002/anie.201304762

258. Zhang, Z.Y., Y.Q. Lai, Z.A. Zhang, K. Zhang, and J.E. Li, Al2O3-coated porous separator for enhanced electrochemical performance of lithium sulfur batteries. Electrochimica Acta, 2014. 129: p. 55-61.10.1016/j.electacta.2014.02.077

259. Ryu, W.-H., T.-H. Yoon, S.H. Song, S. Jeon, Y.-J. Park, and I.-D. Kim, Bifunctional Composite Catalysts Using Co3O4 Nanofibers Immobilized on Nonoxidized Graphene Nanoflakes for HighCapacity and Long-Cycle Li-O2 Batteries. Nano Letters, 2013. 13(9): p. 41904197.10.1021/nl401868q

260. Song, M.J., I.T. Kim, Y.B. Kim, and M.W. Shin, Self-standing, binder-free electrospun Co304/carbon nanofiber composites for non-aqueous Li-air batteries. Electrochimica Acta, 2015. 182: p. 289-296.http://dx.doi.org/10.1016/j.electacta.2015.09.100

261. Guo, Z., C. Li, J. Liu, X. Su, Y. Wang, and Y. Xia, A core-shell-structured TiO2(B) nanofiber@porous RuO2 composite as a carbon-free catalytic cathode for $\mathrm{Li}-\mathrm{O} 2$ batteries. Journal of Materials Chemistry A, 2015. 3(42): p. 21123-21132.10.1039/c5ta06850a

262. Kalubarme, R.S., H.S. Jadhav, D.T. Ngo, G.-E. Park, J.G. Fisher, Y.-I. Choi, W.-H. Ryu, and C.-J. Park, Simple synthesis of highly catalytic carbon-free MnCo2O4@Ni as an oxygen electrode for rechargeable Li-O2 batteries with long-term stability. Scientific Reports, 2015. 5: p. 13266.10.1038/srep13266http://www.nature.com/articles/srep13266\#supplementaryinformation

263. Mitchell, R.R., B.M. Gallant, C.V. Thompson, and Y. Shao-Horn, All-carbon-nanofiber electrodes for high-energy rechargeable Li-O2 batteries. Energy \& Environmental Science, 2011. 4(8): p. 2952-2958.10.1039/c1ee01496j

264. Zhang, G.Q., J.P. Zheng, R. Liang, C. Zhang, B. Wang, M. Au, M. Hendrickson, and E.J. Plichta, $\alpha-$ MnO2/Carbon Nanotube/Carbon Nanofiber Composite Catalytic Air Electrodes for Rechargeable Lithium-air Batteries. Journal of The Electrochemical Society, 2011. 158(7): p. A822A827.10.1149/1.3590736

265. Zhang, G.Q., J.P. Zheng, R. Liang, C. Zhang, B. Wang, M. Hendrickson, and E.J. Plichta, Lithium-Air Batteries Using SWNT/CNF Buckypapers as Air Electrodes. Journal of The Electrochemical Society, 2010. 157(8): p. A953-A956.10.1149/1.3446852

266. Park, S.H. and W.F. Lee, Hierarchically mesoporous flower-like cobalt oxide/carbon nanofiber composites with shell-core structure as anodes for lithium ion batteries. Carbon, 2015. 89: p. 197-207.10.1016/j.carbon.2015.03.039

267. Yang, G., Y. Li, H. Ji, H. Wang, P. Gao, L. Wang, H. Liu, J. Pinto, and X. Jiang, Influence of Mn content on the morphology and improved electrochemical properties of Mn304/MnO@carbon 
nanofiber as anode material for lithium batteries. Journal of Power Sources, 2012. 216: p. 353362.http://dx.doi.org/10.1016/j.jpowsour.2012.05.092

268. Huang, X.S., Separator technologies for lithium-ion batteries. Journal of Solid State Electrochemistry, 2011. 15(4): p. 649-662.DOI 10.1007/s10008-010-1264-9

269. Lee, S.W., S.W. Choi, S.M. Jo, B.D. Chin, D.Y. Kim, and K.Y. Lee, Electrochemical properties and cycle performance of electrospun poly(vinylidene fluoride)-based fibrous membrane electrolytes for Li-ion polymer battery. Journal of Power Sources, 2006. 163(1): p. 41-46.DOI 10.1016/j.jpowsour.2005.11.102

270. Yang, C.R., Z.D. Jia, Z.C. Guan, and L.M. Wang, Polyvinylidene fluoride membrane by novel electrospinning system for separator of Li-ion batteries. Journal of Power Sources, 2009. 189(1): p. 716-720.DOI 10.1016/j.jpowsour.2008.08.060

271. Arora, P. and Z.M. Zhang, Battery separators. Chemical Reviews, 2004. 104(10): p. 44194462.Doi 10.1021/Cr020738u

272. Nunes-Pereira, J., C.M. Costa, and S. Lanceros-Mendez, Polymer composites and blends for battery separators: State of the art, challenges and future trends. Journal of Power Sources, 2015. 281: p. 378-398.DOI 10.1016/j.jpowsour.2015.02.010

273. Cho, T.H., M. Tanaka, H. Ohnishi, Y. Kondo, M. Yoshikazu, T. Nakamura, and T. Sakai, Composite nonwoven separator for lithium-ion battery: Development and characterization. Journal of Power Sources, 2010. 195(13): p. 4272-4277.DOI 10.1016/j.jpowsour.2010.01.018

274. Lee, Y.M., J.W. Kim, N.S. Choi, J.A. Lee, W.H. Seol, and J.K. Park, Novel porous separator based on $P V d F$ and $P E$ non-woven matrix for rechargeable lithium batteries. Journal of Power Sources, 2005. 139(1-2): p. 235-241.DOI 10.1016/j.jpowsour.2004.06.055

275. Li, S.L., X.P. Ai, H.X. Yang, and Y.L. Cao, A polytriphenylamine-modified separator with reversible overcharge protection for 3.6 V-class lithium-ion battery. Journal of Power Sources, 2009. 189(1): p. 771-774.DOI 10.1016/j.jpowsour.2008.08.006

276. Lee, Y.S., Y.B. Jeong, and D.W. Kim, Cycling performance of lithium-ion batteries assembled with a hybrid composite membrane prepared by an electrospinning method. Journal of Power Sources, 2010. 195(18): p. 6197-6201.DOI 10.1016/j.jpowsour.2009.11.012

277. Xiong, M., H. Tang, Y. Wang, and M. Pan, Ethylcellulose-coated polyolefin separators for lithiumion batteries with improved safety performance. Carbohydrate Polymers, 2014. 101(0): p. 11401146.http://dx.doi.org/10.1016/j.carbpol.2013.10.073

278. Kuribayashi, I., Characterization of composite cellulosic separators for rechargeable lithium-ion batteries. Journal of Power Sources, 1996. 63(1): p. 87-91.Doi 10.1016/S0378-7753(96)02450-0

279. Zhang, S.S., A review on the separators of liquid electrolyte Li-ion batteries. Journal of Power Sources, 2007. 164(1): p. 351-364.10.1016/j.jpowsour.2006.10.065

280. Jiang, W., Z.H. Liu, Q.S. Kong, J.H. Yao, C.J. Zhang, P.X. Han, and G.L. Cui, A high temperature operating nanofibrous polyimide separator in Li-ion battery. Solid State lonics, 2013. 232: p. 4448.DOI 10.1016/j.ssi.2012.11.010

281. Kritzer, P., Nonwoven support material for improved separators in Li-polymer batteries. Journal of Power Sources, 2006. 161(2): p. 1335-

1340.http://dx.doi.org/10.1016/j.jpowsour.2006.04.142

282. Kim, J.H., J.H. Kim, E.S. Choi, H.K. Yu, J.H. Kim, Q.L. Wu, S.J. Chun, S.Y. Lee, and S.Y. Lee, Colloidal silica nanoparticle-assisted structural control of cellulose nanofiber paper separators for lithiumion batteries. Journal of Power Sources, 2013. 242: p. 533-540.DOI 10.1016/j.jpowsour.2013.05.142

283. Chun, S.J., E.S. Choi, E.H. Lee, J.H. Kim, S.Y. Lee, and S.Y. Lee, Eco-friendly cellulose nanofiber paper-derived separator membranes featuring tunable nanoporous network channels for 
lithium-ion batteries. Journal of Materials Chemistry, 2012. 22(32): p. 16618-16626.Doi 10.1039/C2jm32415f

284. Zhang, J.J., L.P. Yue, Q.S. Kong, Z.H. Liu, X.H. Zhou, C.J. Zhang, S.P. Pang, X.J. Wang, J.H. Yao, and G.L. Cui, A Heat-Resistant Silica Nanoparticle Enhanced Polysulfonamide Nonwoven Separator for High-Performance Lithium Ion Battery. Journal of the Electrochemical Society, 2013. 160(6): p. A769-A774.Doi 10.1149/2.043306jes

285. Cho, T.-H., M. Tanaka, H. Onishi, Y. Kondo, T. Nakamura, H. Yamazaki, S. Tanase, and T. Sakai, Battery performances and thermal stability of polyacrylonitrile nano-fiber-based nonwoven separators for Li-ion battery. Journal of Power Sources, 2008. 181(1): p. 155160.http://dx.doi.org/10.1016/j.jpowsour.2008.03.010

286. Ye, W., J. Zhu, X. Liao, S. Jiang, Y. Li, H. Fang, and H. Hou, Hierarchical three-dimensional micro/nano-architecture of polyaniline nanowires wrapped-on polyimide nanofibers for high performance lithium-ion battery separators. Journal of Power Sources, 2015. 299: p. 417424.http://dx.doi.org/10.1016/j.jpowsour.2015.09.037

287. Cho, T.H., T. Sakai, S. Tanase, K. Kimura, Y. Kondo, T. Tarao, and M. Tanaka, Electrochemical Performances of Polyacrylonitrile Nanofiber-Based Nonwoven Separator for Lithium-Ion Battery. Electrochemical and Solid-State Letters, 2007. 10(7): p. A159-A162.10.1149/1.2730727

288. Jeschke, S., M. Mutke, Z. Jiang, B. Alt, and H.-D. Wiemhoefer, Study of Carbamate-Modified Disiloxane in Porous PVDF-HFP Membranes: New Electrolytes/Separators for Lithiumlon Batteries. Chemphyschem, 2014. 15(9): p. 1761-1771.10.1002/cphc.201400065

289. Li, H., Y.-M. Chen, X.-T. Ma, J.-L. Shi, B.-K. Zhu, and L.-P. Zhu, Gel polymer electrolytes based on active PVDF separator for lithium ion battery. I: Preparation and property of PVDF/poly(dimethylsiloxane) blending membrane. Journal of Membrane Science, 2011. 379(12): p. 397-402.10.1016/j.memsci.2011.06.008

290. Li, H., C.-E. Lin, J.-L. Shi, X.-T. Ma, B.-K. Zhu, and L.-P. Zhu, Preparation and characterization of safety PVDF/P(MMA-co-PEGMA) active separators by studying the liquid electrolyte distribution in this kind of membrane. Electrochimica Acta, 2014. 115: p. 317325.10.1016/j.electacta.2013.10.183

291. Xi, J.Y., X.P. Qiu, and L.Q. Chen, PVDF-PEO/ZSM-5 based composite microporous polymer electrolyte with novel pore configuration and ionic conductivity. Solid State Ionics, 2006. 177(78): p. 709-713.10.1016/j.ssi.2006.01.032

292. Xi, J.Y., X.P. Qiu, J. Li, X.Z. Tang, W.T. Zhu, and L.Q. Chen, PVDF-PEO blends based microporous polymer electrolyte: Effect of PEO on pore configurations and ionic conductivity. Journal of Power Sources, 2006. 157(1): p. 501-506.10.1016/j.jpowsour.2005.08.009

293. Zhai, W., H.-j. Zhu, L. Wang, X.-m. Liu, and H. Yang, Study of PVDF-HFP/PMMA blended microporous gel polymer electrolyte incorporating ionic liquid BMIM BF4 for Lithium ion batteries. Electrochimica Acta, 2014. 133: p. 623-630.10.1016/j.electacta.2014.04.076

294. Wang, H.P., H.T. Huang, and S.L. Wunder, Novel microporous poly(vinylidene fluoride) blend electrolytes for lithium-ion batteries. Journal of the Electrochemical Society, 2000. 147(8): p. 2853-2861.10.1149/1.1393616

295. Song, J.Y., Y.Y. Wang, and C.C. Wan, Review of gel-type polymer electrolytes for lithium-ion batteries. Journal of Power Sources, 1999. 77(2): p. 183-197.10.1016/s0378-7753(98)00193-1

296. Yoshio, M., R.J. Brodd, and A. Kozawa, Lithium-ion batteries : science and technologies. 2009, New York: Springer. xxvi, $452 \mathrm{p}$.

297. Juang, R.-S., C.-T. Hsieh, P.-A. Chen, and Y.-F. Chen, Microwave-assisted synthesis of titania coating onto polymeric separators for improved lithium-ion battery performance. Journal of Power Sources, 2015. 286(0): p. 526-533.http://dx.doi.org/10.1016/j.jpowsour.2015.04.023 
298. Choi, J.A., S.H. Kim, and D.W. Kim, Enhancement of thermal stability and cycling performance in lithium-ion cells through the use of ceramic-coated separators. Journal of Power Sources, 2010. 195(18): p. 6192-6196.DOI 10.1016/j.jpowsour.2009.11.020

299. Jeong, H.S. and S.Y. Lee, Closely packed SiO2 nanoparticles/poly/vinylidene fluoridehexafluoropropylene) layers-coated polyethylene separators for lithium-ion batteries. Journal of Power Sources, 2011. 196(16): p. 6716-6722.DOI 10.1016/j.jpowsour.2010.11.037

300. Zhang, Z.A., Z.Y. Zhang, J. Li, and Y.Q. Lai, Polydopamine-coated separator for high-performance lithium-sulfur batteries. Journal of Solid State Electrochemistry, 2015. 19(6): p. 17091715.10.1007/s10008-015-2797-8

301. Fang, L.F., J.L. Shi, H. Li, B.K. Zhu, and L.P. Zhu, Construction of Porous PVDF Coating Layer and Electrochemical Performances of the Corresponding Modified Polyethylene Separators for Lithium Ion Batteries. Journal of Applied Polymer Science, 2014. 131(21).4103610.1002/app.41036

302. Liu, H., Z. Dai, J. Xu, B. Guo, and X. He, Effect of silica nanoparticles/poly/vinylidene fluoridehexafluoropropylene) coated layers on the performance of polypropylene separator for lithiumion batteries. Journal of Energy Chemistry, 2014. 23(5): p. 582-586.10.1016/s20954956(14)60188-1

303. Liu, H., J. Xu, B. Guo, and X. He, Effect of Al2O3/SiO2 composite ceramic layers on performance of polypropylene separator for lithium-ion batteries. Ceramics International, 2014. 40(9): $p$. 14105-14110.10.1016/j.ceramint.2014.05.142

304. Prasanna, K., C.-S. Kim, and C.W. Lee, Effect of SiO2 coating on polyethylene separator with different stretching ratios for application in lithium ion batteries. Materials Chemistry and Physics, 2014. 146(3): p. 545-550.10.1016/j.matchemphys.2014.04.014

305. Shi, C., P. Zhang, L. Chen, P. Yang, and J. Zhao, Effect of a thin ceramic-coating layer on thermal and electrochemical properties of polyethylene separator for lithium-ion batteries. Journal of Power Sources, 2014. 270: p. 547-553.10.1016/j.jpowsour.2014.07.142

306. Wang, J., Z. Hu, X. Yin, Y. Li, H. Huo, J. Zhou, and L. Li, Alumina/Phenolphthalein Polyetherketone Ceramic Composite Polypropylene Separator Film for Lithium Ion Power Batteries. Electrochimica Acta, 2015. 159: p. 61-65.10.1016/j.electacta.2015.01.208

307. Xiao, W., L. Zhao, Y. Gong, S. Wang, J. Liu, and C. Yan, Preparation of high performance lithiumion batteries with a separator-cathode assembly. Rsc Advances, 2015. 5(43): p. 3418434190.10.1039/c5ra03769g

308 Jung, Ji-Won, Lee C.L, Yu, S and Kim II-Doo, Electrospun nanofibers as a platform for advanced secondary batteries: a comprehensive review, J. Mater. Chem. A, 2016, 4, 703, DOI: $10.1039 / c 5 t a 06844 d$

309 Lee, H., Yanilmaz, M., Toprakci, O., Fu, K., Zhang, XW., A review of recent developments in membrane separators for rechargeable lithium-ion batteries, Energy Environ. Sci., 2014, 7, 3857, DOI: $10.1039 / \mathrm{c} 4 \mathrm{ee} 01432 \mathrm{~d}$ 
Figures

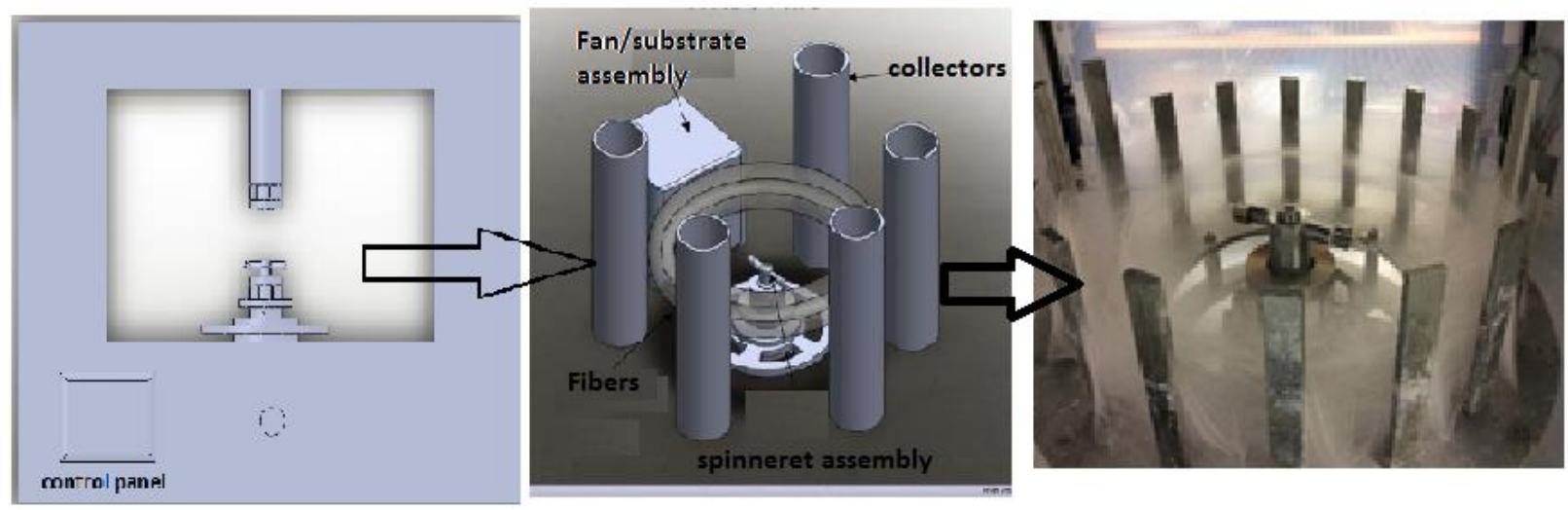

Figure 1a:

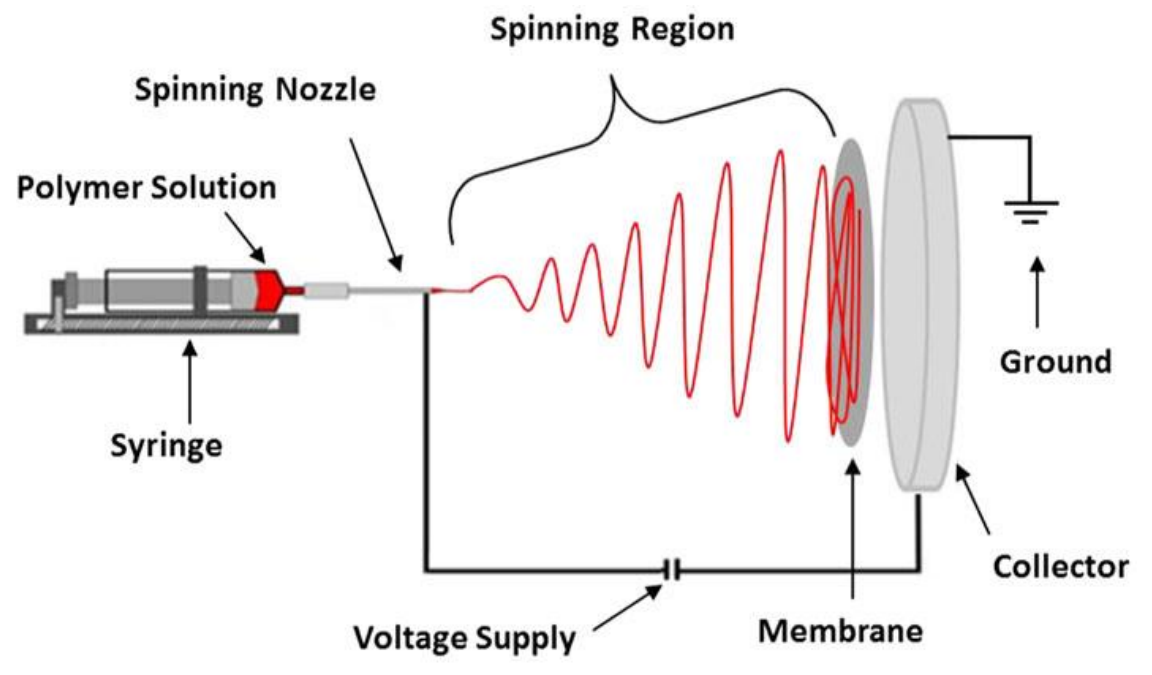

Figure 1b: 

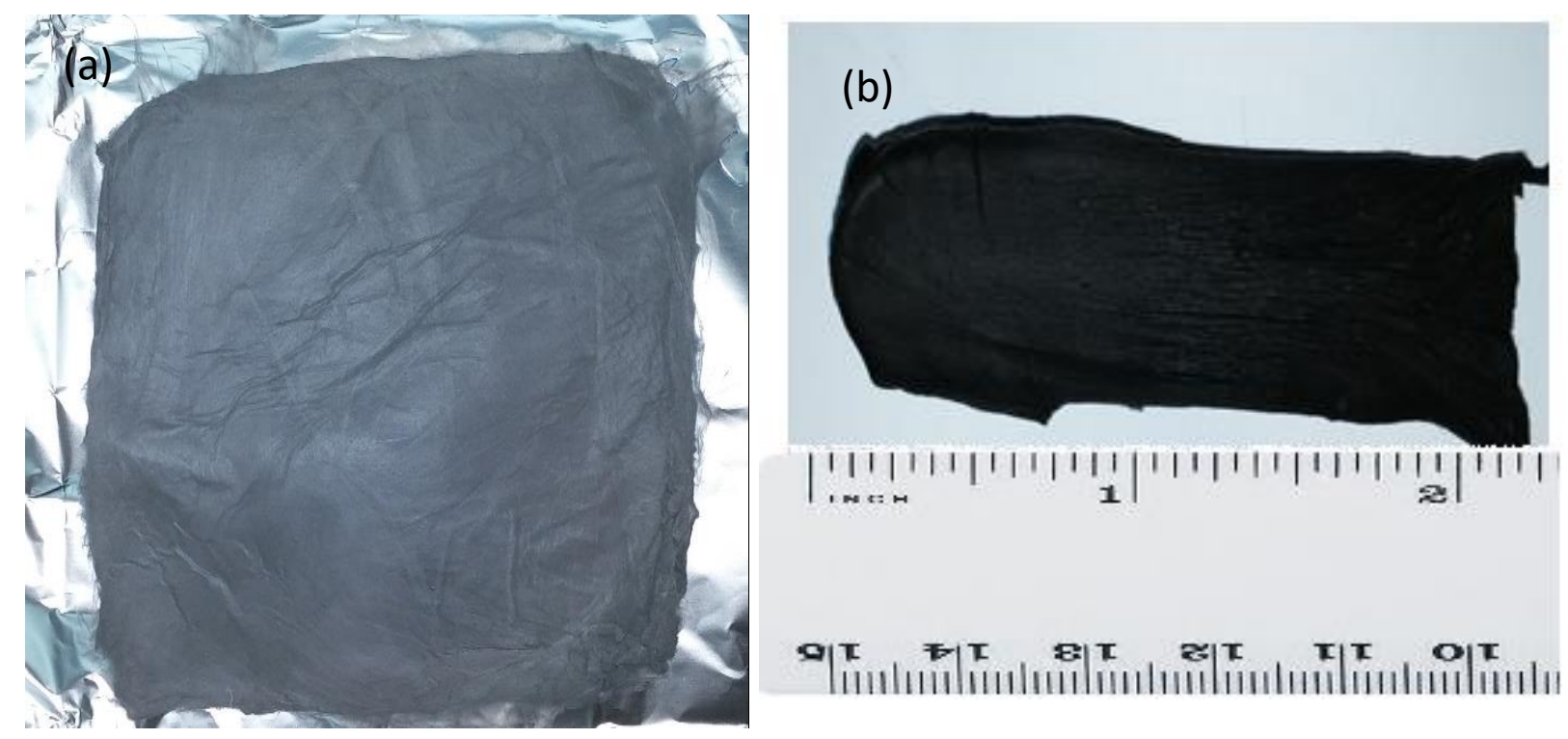

Figure 2: 

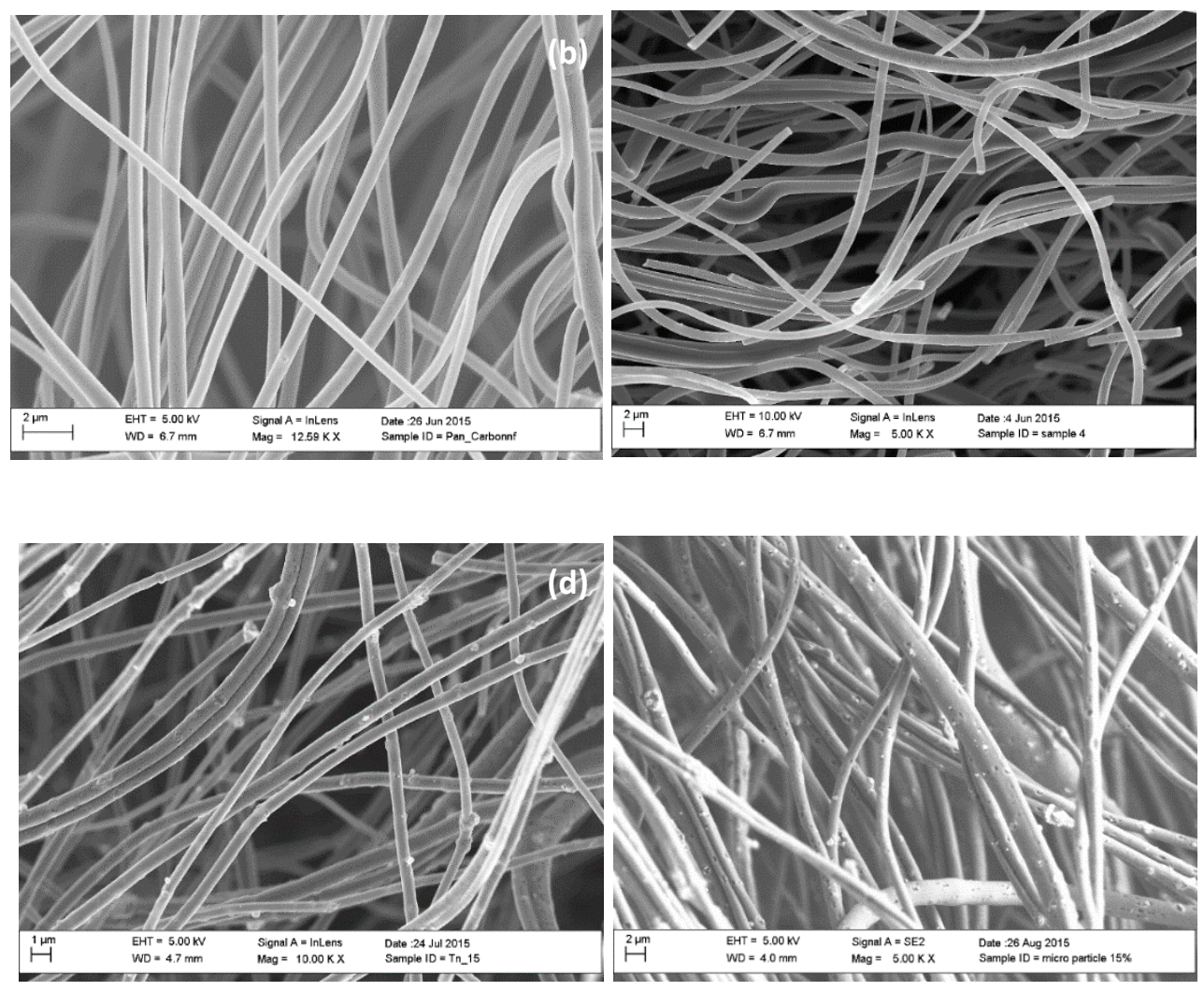

Figure 3: 


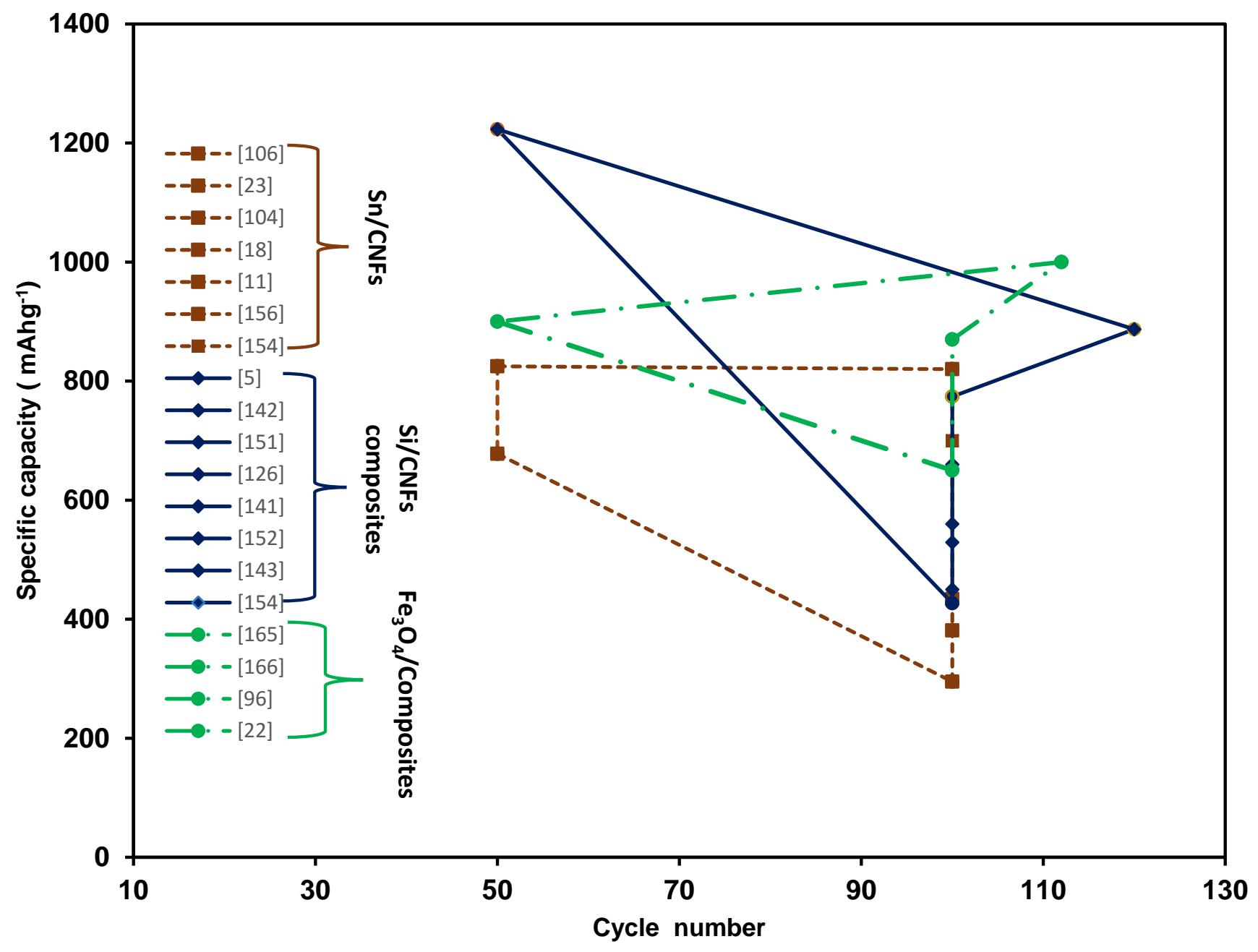

Figure 4: 


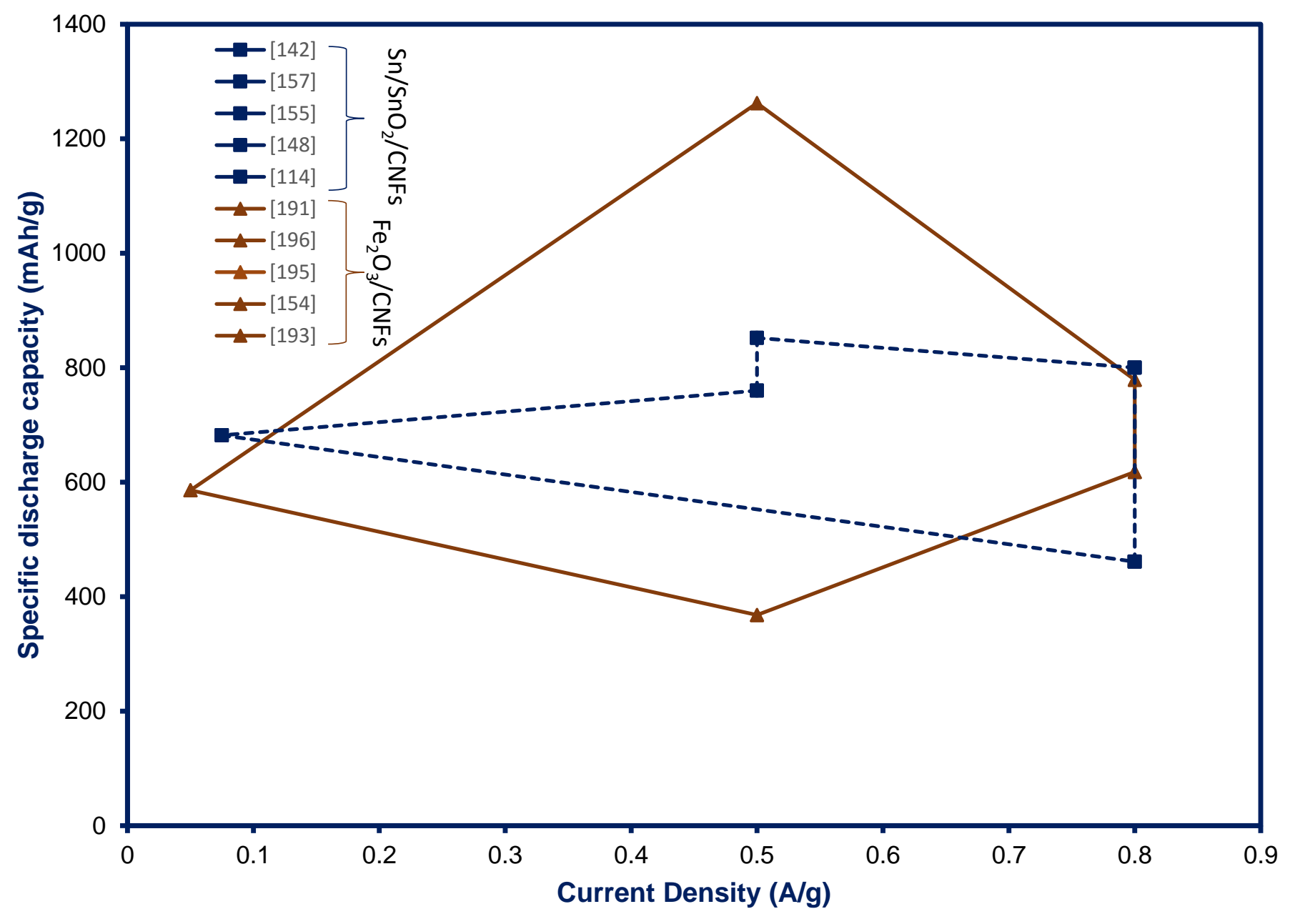

Figure 5: 

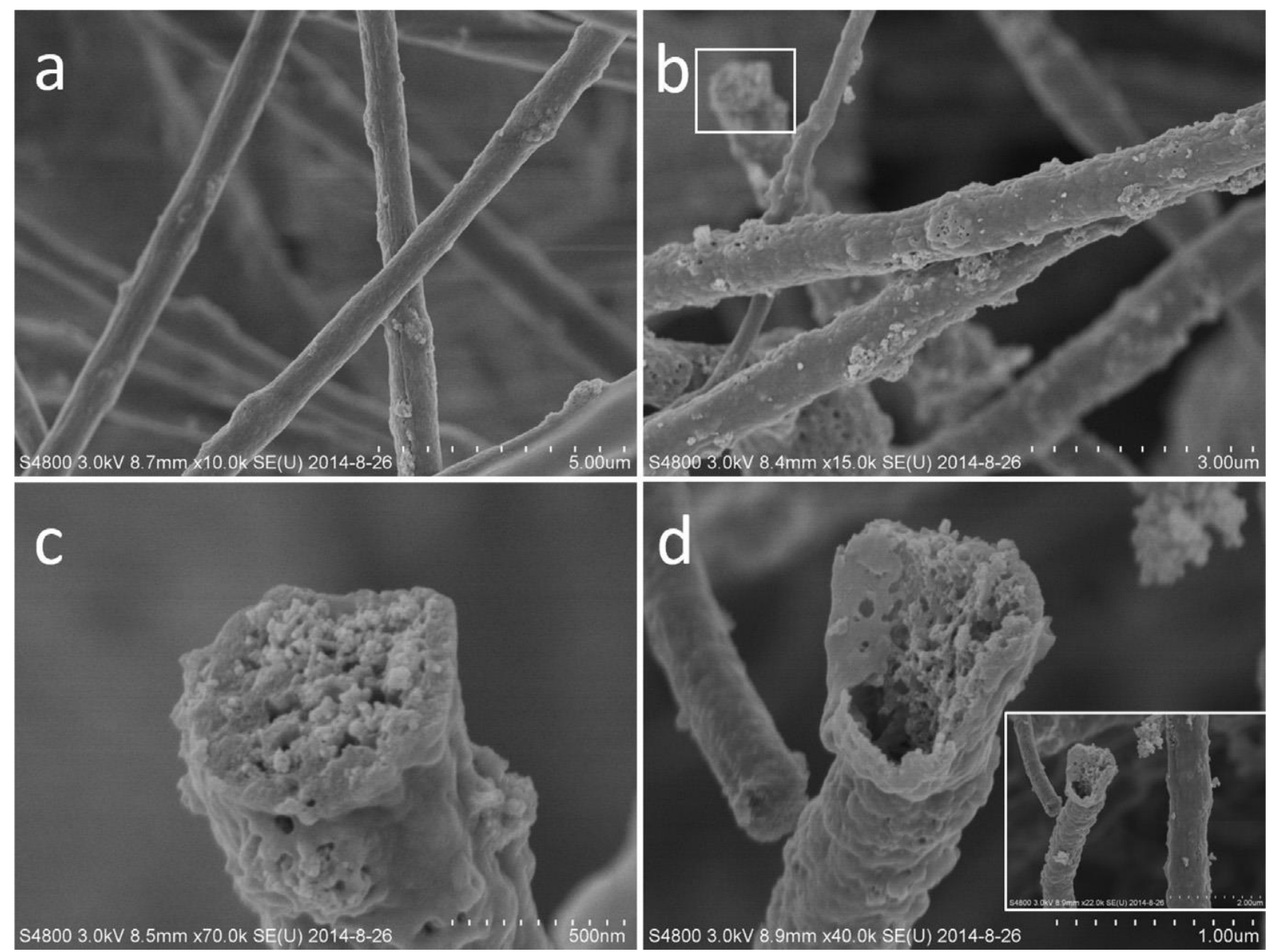

Figure 6: 


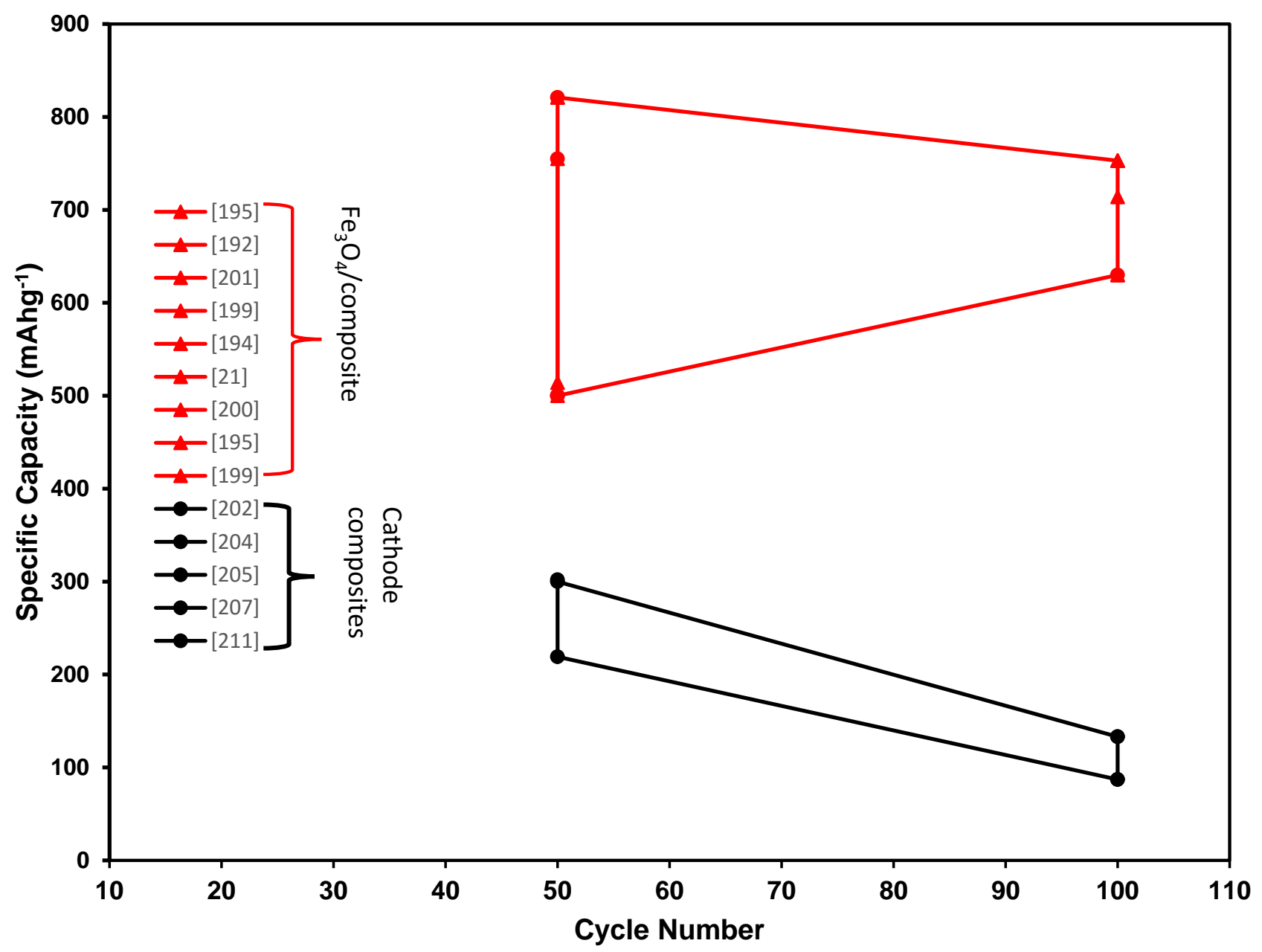

Figure 7: 

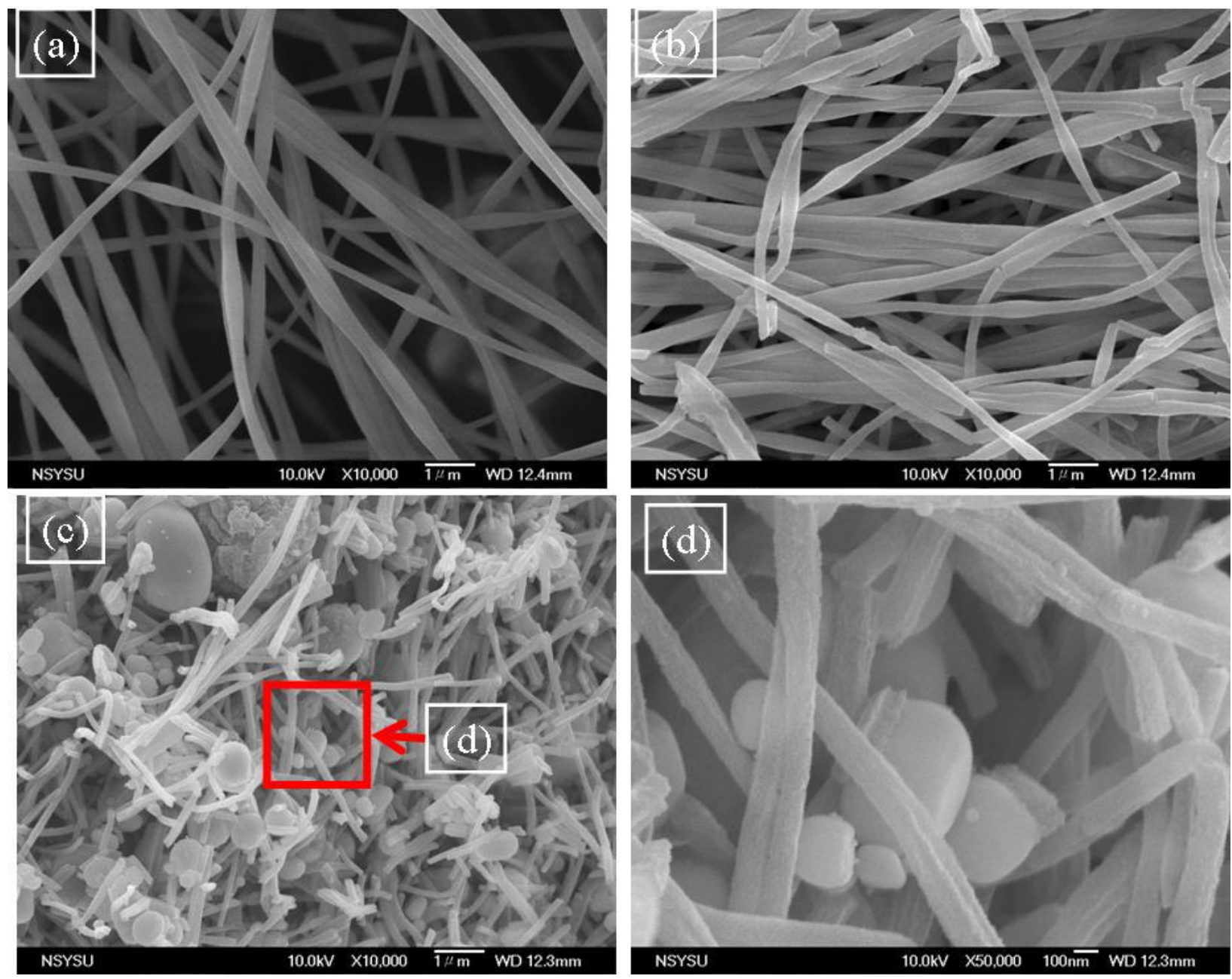

Figure 8: 

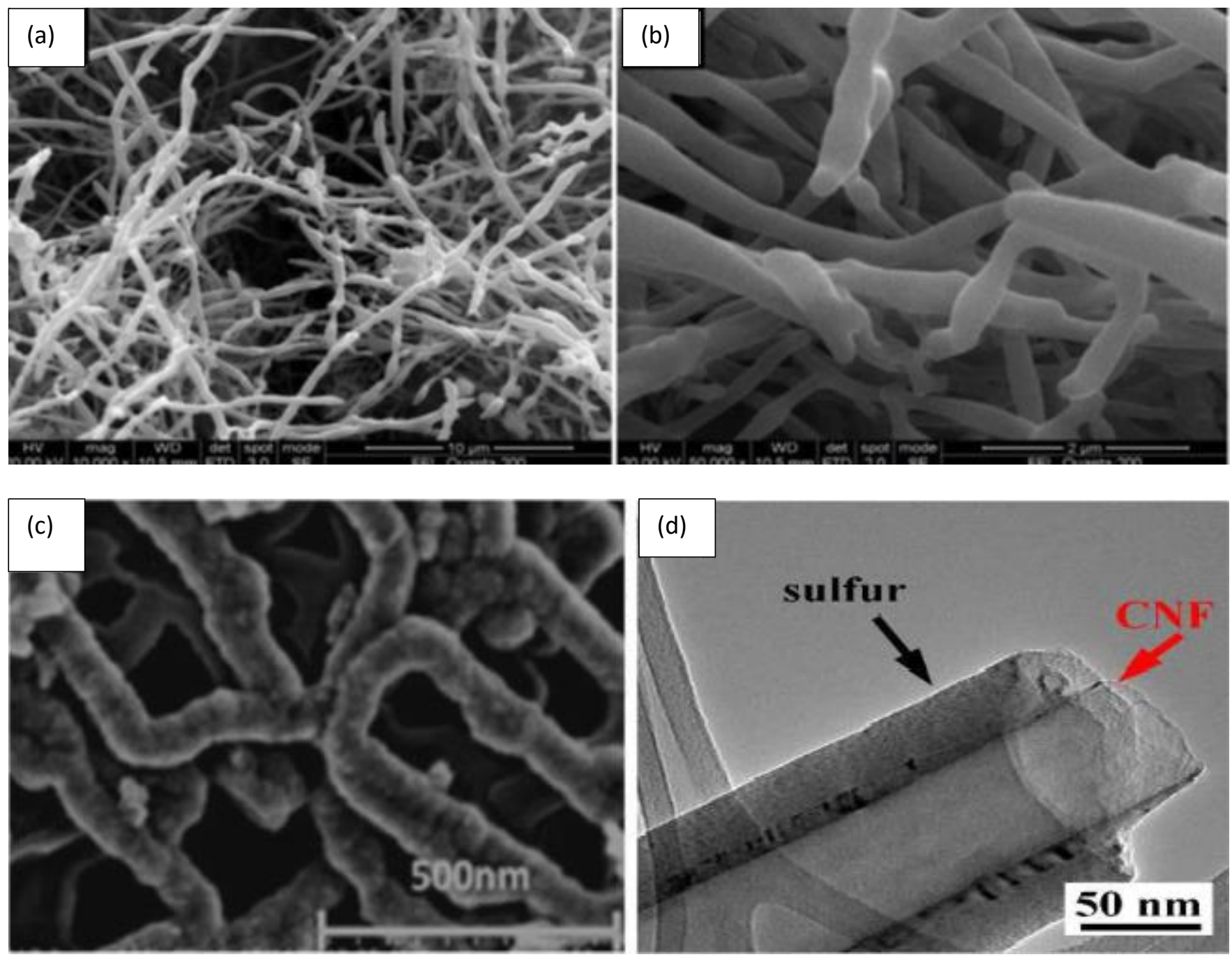

Figure 9 

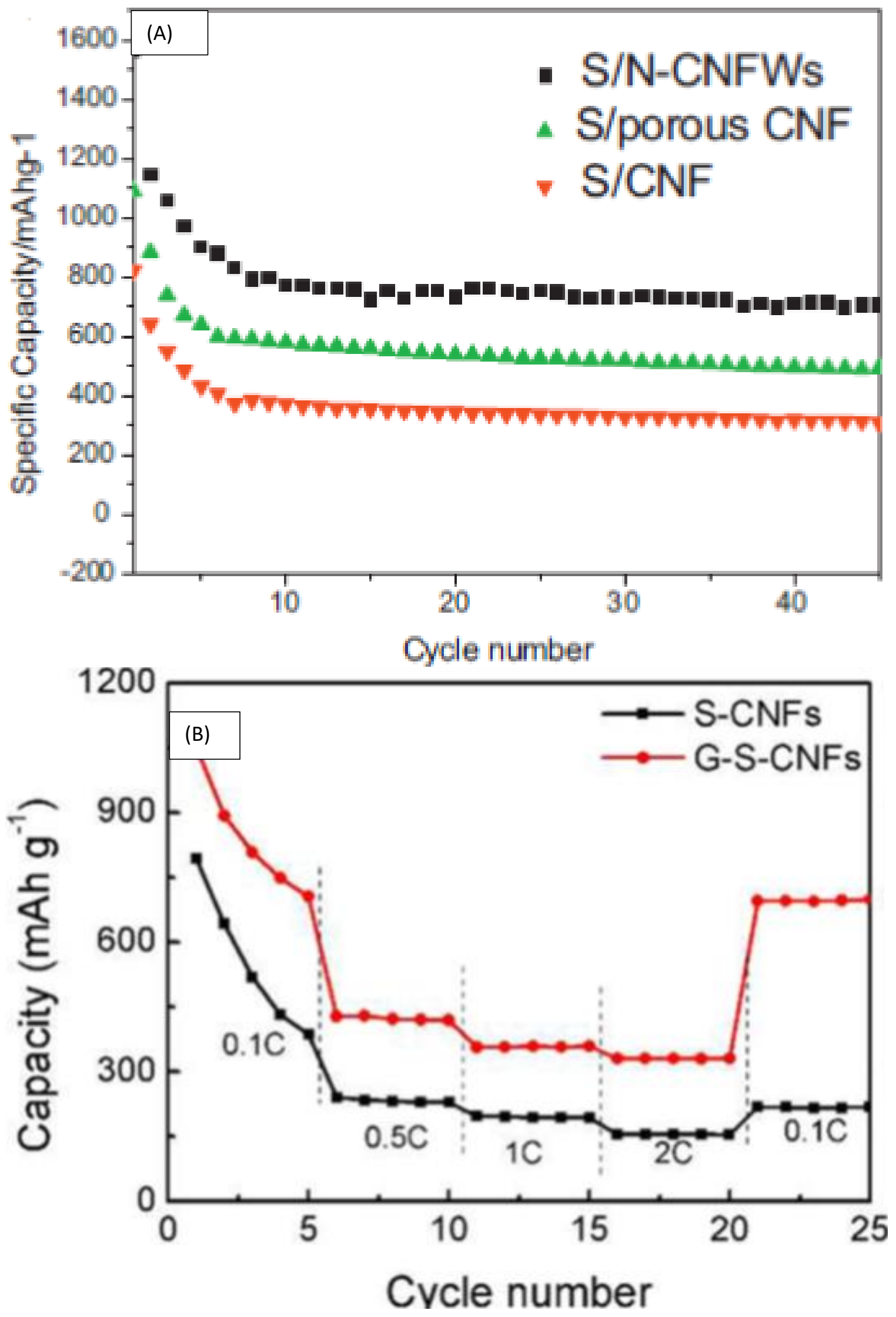

Figure 10 

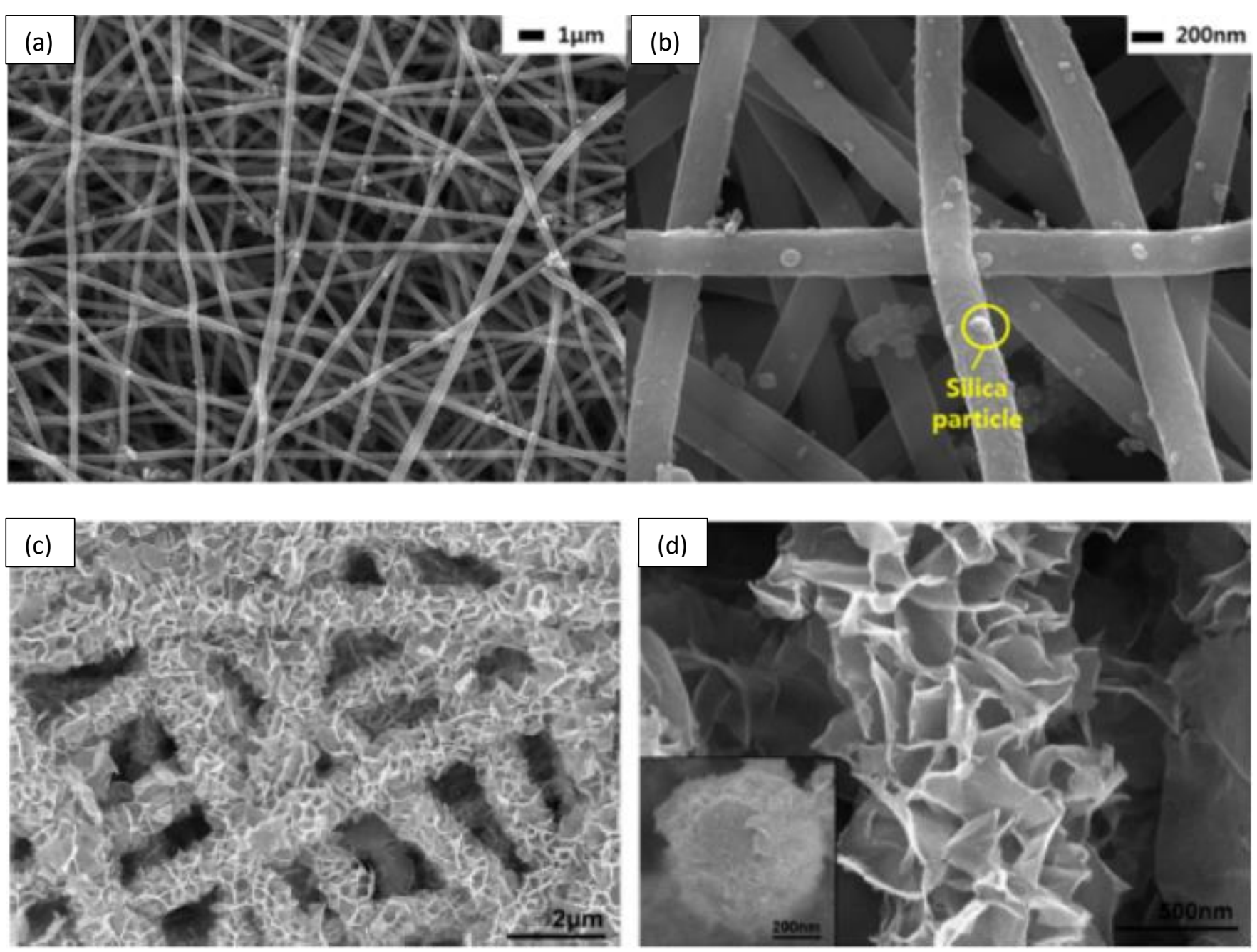

Figure 11 

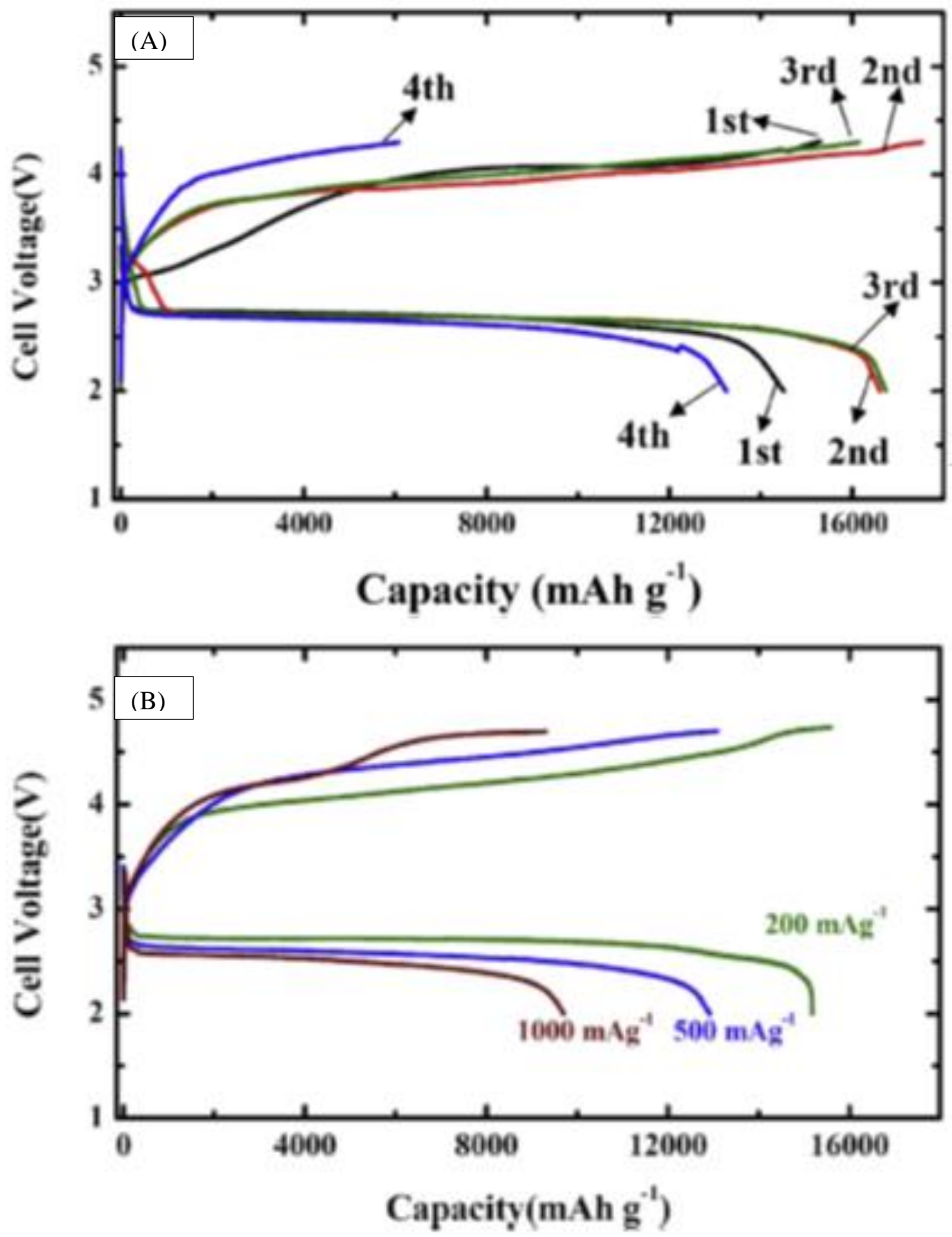

Figure 12: 


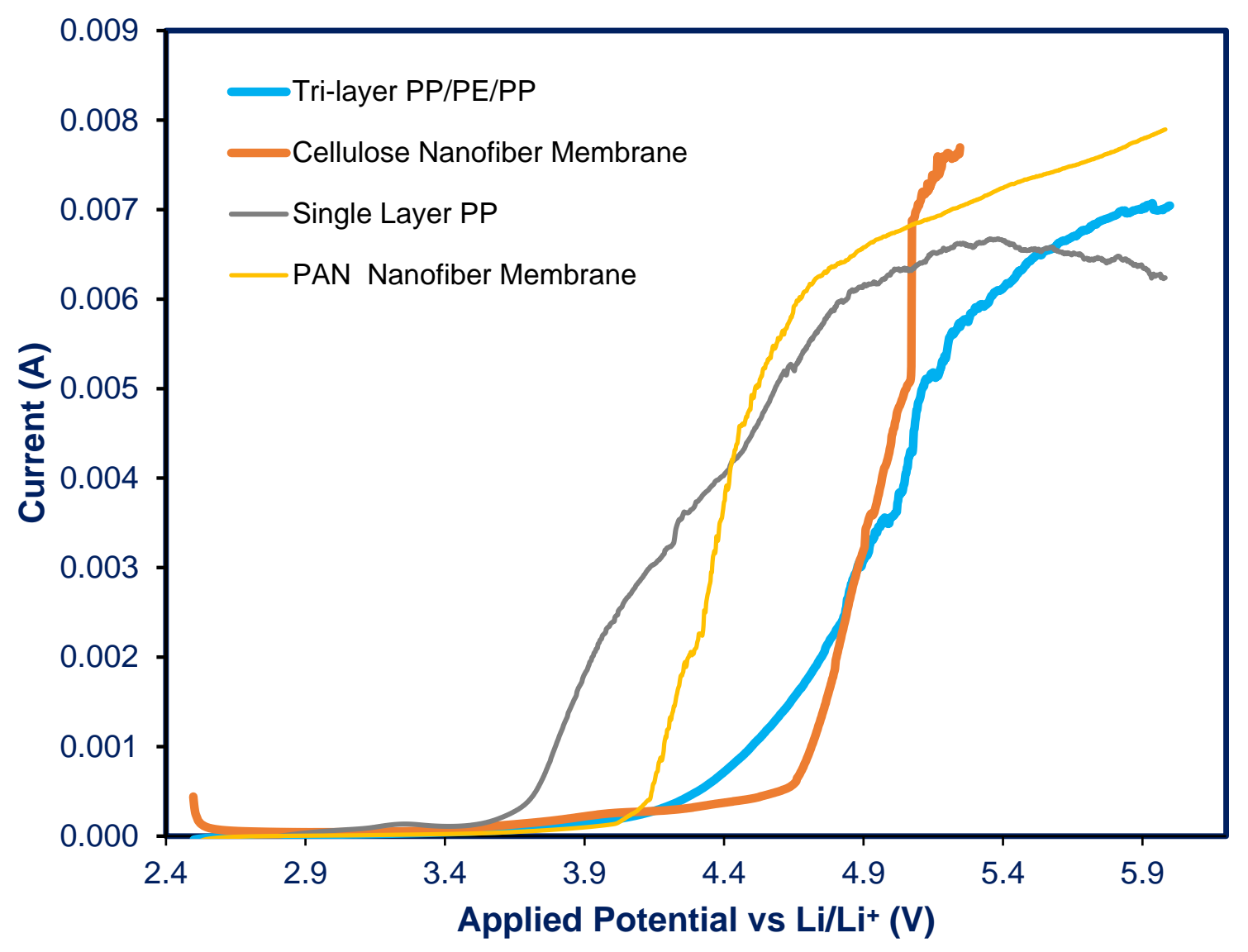

Figure 13: 


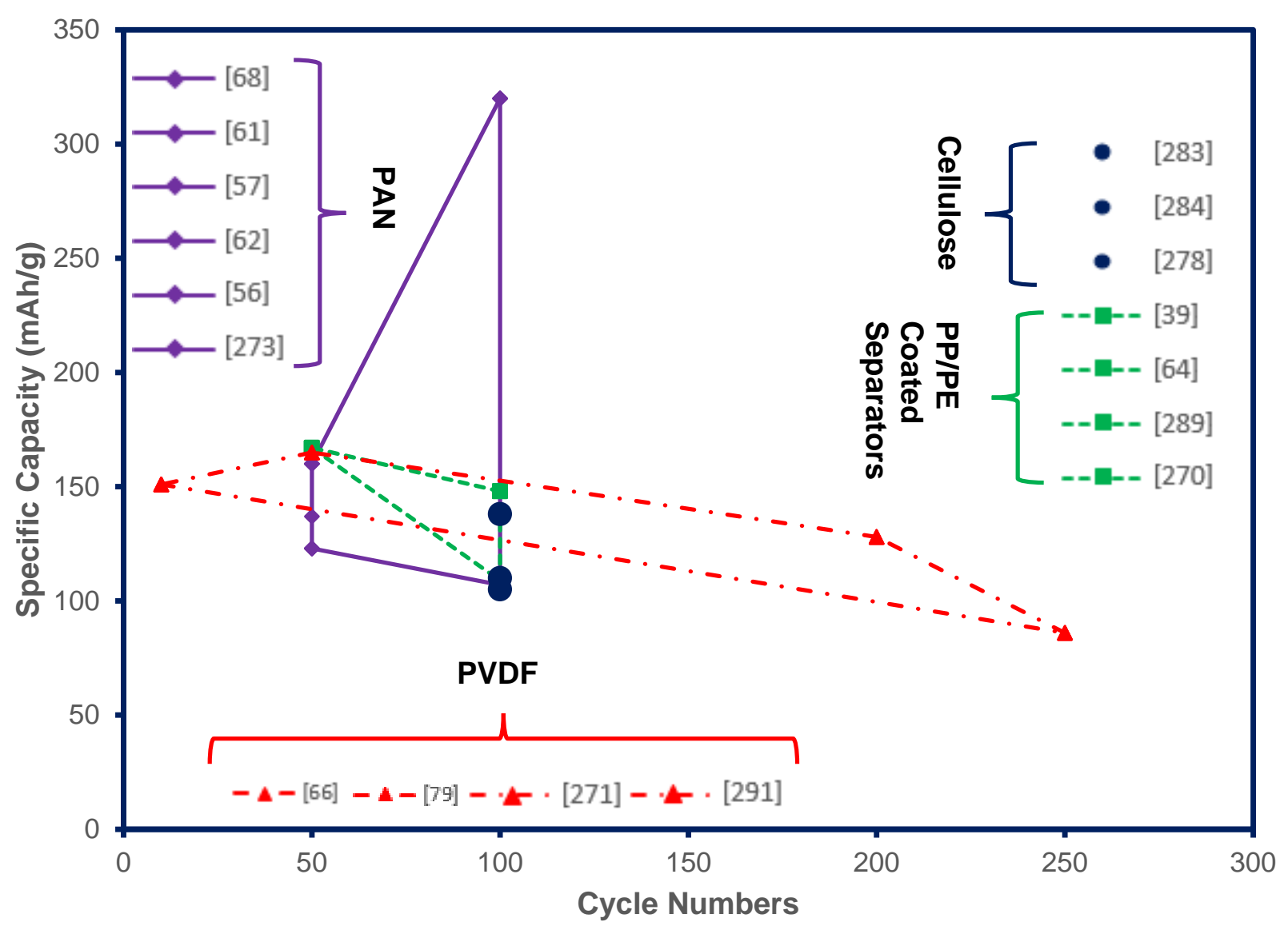

Figure 14: 

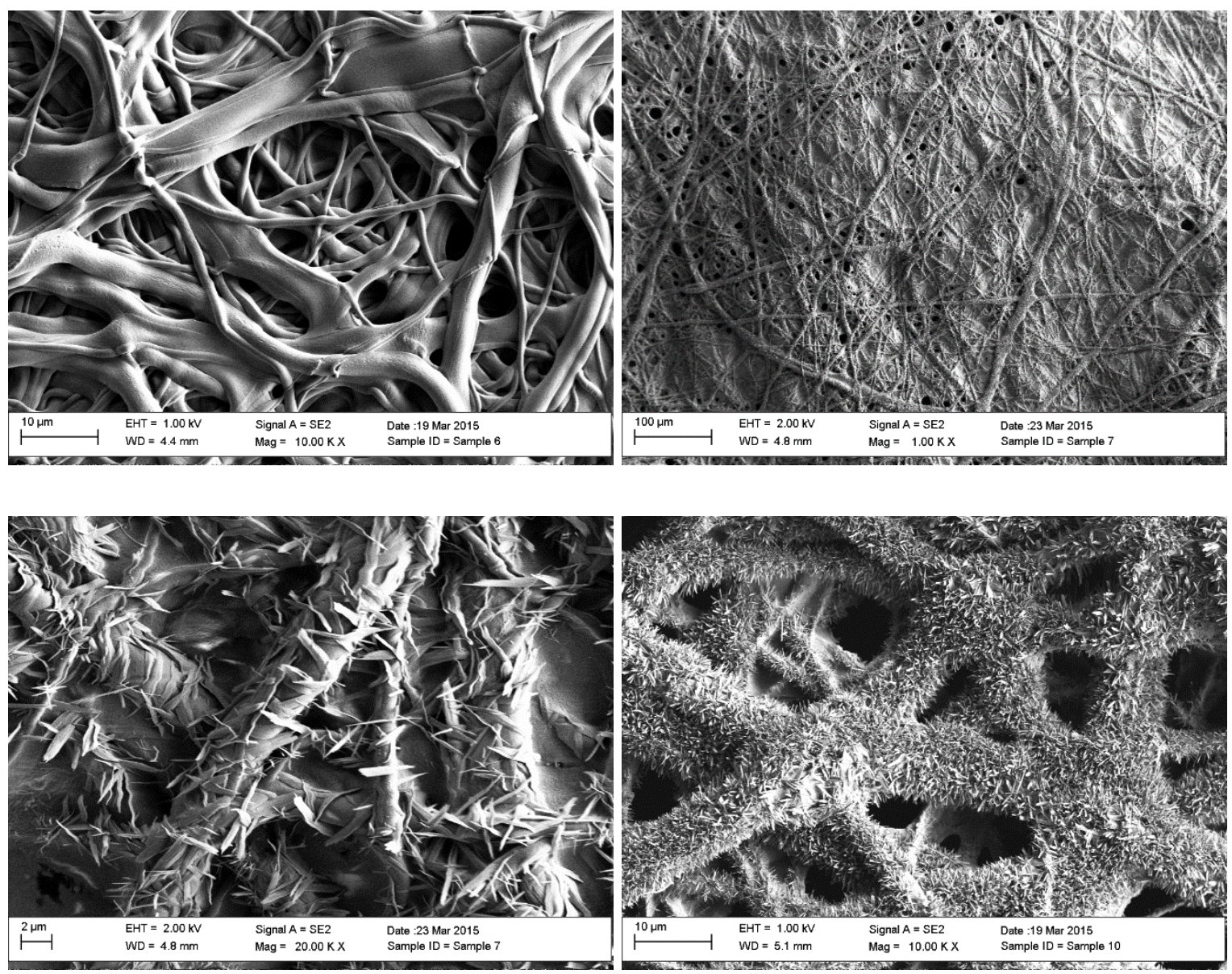

Figure 15: 

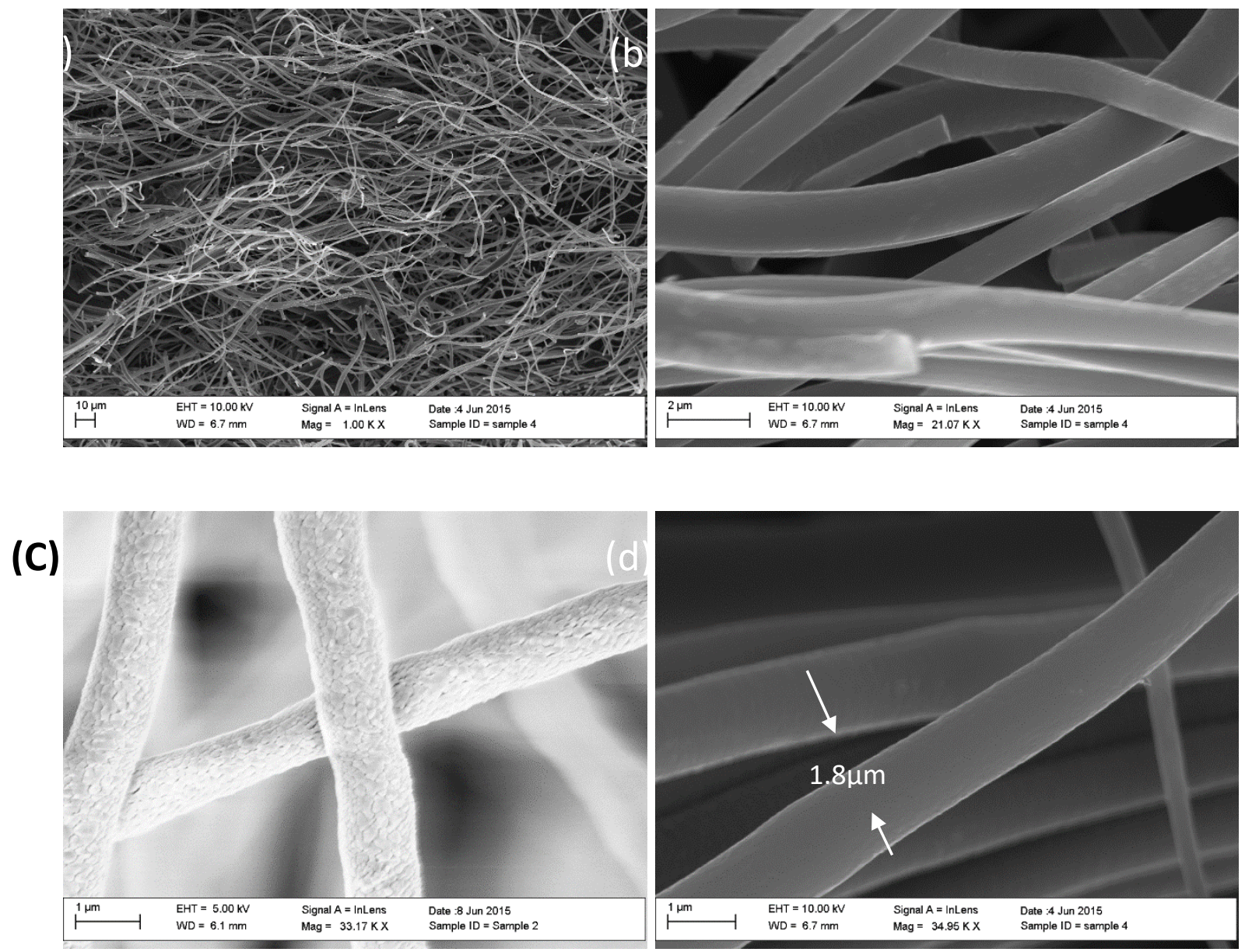

Figure 16: 

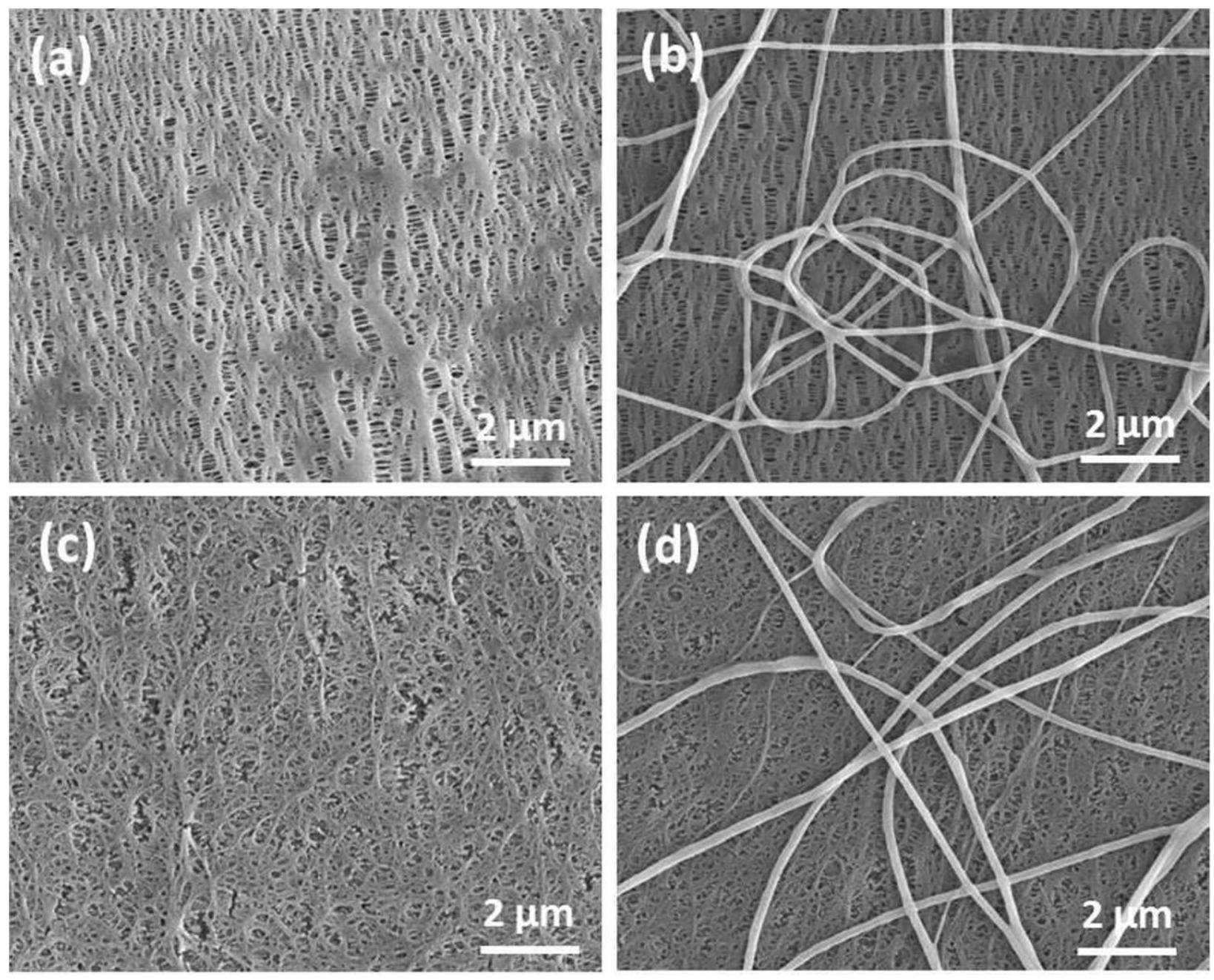

Figure 17: 